\title{
Food additive "lauric acid" possess non-toxic profile on biochemical, haematological and histopathological studies in female Sprague Dawley (SD) rats
}

\author{
Hidayat Ullah Khan ${ }^{1}$, Khurram Aamir ${ }^{1}$, Sreenivas Patro Sisinthy ${ }^{1}$, Narendra Babu Shivanagere Nagojappa ${ }^{1}$, \\ Aditya Arya ${ }^{\text {Corresp. 2, 3, } 4}$ \\ ${ }^{1}$ School of Pharmacy, Faculty of Health and Medical Sciences, Taylor's University, Subang jaya, Selangor, Malaysia \\ Department of Pharmacology and Therapeutics, School of Medicine, Faculty of Health and Medical Sciences, Taylor's University, Subang Jaya, Malaysia, \\ Taylor's University, Subang jaya, Selangor, Malaysia \\ 3 Department of Pharmacology and Therapeutics, Faculty of Medicine, Dentistry and Health Sciences, University of Melbourne, Parkville, VIC, Australia, \\ University of Melbourne, Melbourne, Parkville VIC, Australia \\ 4 Malaysian Institute of Pharmaceuticals and Nutraceuticals, (IPHARM), Bukit Gelugor Pulau, Pinang, Malaysia \\ Corresponding Author: Aditya Arya \\ Email address: aditya.arya@taylors.edu.my
}

Background: Lauric acid (LA), a common constituent of coconut oil is used as food additives and supplements in various formulations. Despite various potential pharmacological properties, no scientific evidence on its dose-related toxicity and safety is available till date.

Objective: The current study was conducted to evaluate acute oral toxicity of LA on normal rats.

Methods: Study was conducted in accordance with the Organization for Economic Co-operation and Development guidelines (OECD 423) with slight modifications. LA was administered orally to female Sprague Dawley (SD) rats ( $n=6 / \mathrm{group}$ ) at a single dose of 300 and $2000 \mathrm{mg} / \mathrm{kg}$ body weight respectively, while normal control received vehicle only. Animals from all the three groups were monitored for any behavioural and toxicological changes and mortality for two weeks. Food and fluid consumption, body weight was monitored on daily basis. At the end (on day $15^{\text {th }}$ ) of the experimental period, blood was collected for haematological and biochemical analysis. Further, all the animals were euthanized, and internal organs were harvested for histopathological investigation using four different stainings; haematoxylin and eosin, Masson trichrome, Periodic Acid Schiff and Picro Sirius Red for gross pathology through microscopical observation.

Results: Study result showed no LA treatment-related mortality and morbidity at two different dosages. Daily food and water consumption, body weight, relative organ weight, haematological, and biochemical analysis were observed to be normal with no severe alterations to the internal tissues.

Conclusion: Current finding suggests that single oral administration of LA, even up to $2000 \mathrm{mg} / \mathrm{kg}$ body weight did not exhibit any signs of toxicity in SD rats, thus, safe to be used on disease model in animals. 
1 Food additive "lauric acid" possess non-toxic profile on biochemical, 2 haematological and histopathological studies in female Sprague 3 Dawley (SD) rats

4

5 Hidayat Ullah Khan ${ }^{1}$, Khurram Aamir ${ }^{1}$, Sreenivas Patro Sisinthy ${ }^{1}$, Narendra Babu Shivanagere Nagojappa ${ }^{1}$, 6 Aditya Arya $2,3,4^{* *}$

7

8

${ }^{1}$ School of Pharmacy, Faculty of Health and Medical Sciences, Taylor's University, Subang Jaya, Malaysia

${ }^{2}$ Department of Pharmacology and Therapeutics, School of Medicine, Faculty of Health and Medical Sciences,

Taylor's University, Subang Jaya, Malaysia

${ }^{3}$ Department of Pharmacology and Therapeutics, Faculty of Medicine, Dentistry and Health Sciences, University of Melbourne, Parkville, VIC, Australia

${ }^{4}$ Malaysian Institute of Pharmaceuticals and Nutraceuticals (IPHARM), Bukit Gambir, Gelugor, Pulau Pinang, Malaysia

Corresponding Author:

Correspondence:

Aditya Arya, Ph.D.

Associate Professor

Department of Pharmacology and Therapeutics

School of Medicine

Faculty of Health and Medical Sciences

Taylor's University

Subang Jaya, Malaysia

Tel: +60-3-5629-5653

Email: aditya.arya@taylors.edu.my; aditya.arya@unimelb.edu.au 


\section{Abstract}

Background: Lauric acid (LA), a common constituent of coconut oil is used as food additives and supplements in various formulations. Despite various potential pharmacological 57 in animals. properties, no scientific evidence on its dose-related toxicity and safety is available till date. Objective: The current study was conducted to evaluate acute oral toxicity of LA on normal rats. Methods: Study was conducted in accordance with the Organization for Economic Co-operation and Development guidelines (OECD 423) with slight modifications. LA was administered orally to female Sprague Dawley (SD) rats ( $n=6 /$ group) at a single dose of 300 and $2000 \mathrm{mg} / \mathrm{kg}$ body weight respectively, while normal control received vehicle only. Animals from all the three groups were monitored for any behavioural and toxicological changes and mortality for two weeks. Food and fluid consumption, body weight was monitored on daily basis. At the end (on day $15^{\text {th }}$ ) of the experimental period, blood was collected for haematological and biochemical analysis. Further, all the animals were euthanized, and internal organs were harvested for histopathological investigation using four different stainings; haematoxylin and eosin, Masson trichrome, Periodic Acid Schiff and Picro Sirius Red for gross pathology through microscopical observation. Results: Study result showed no LA treatment-related mortality and morbidity at two different dosages. Daily food and water consumption, body weight, relative organ weight, haematological, and biochemical analysis were observed to be normal with no severe alterations to the internal tissues. Conclusion: Current finding suggests that single oral administration of LA, even up to $2000 \mathrm{mg} / \mathrm{kg}$ body weight did not exhibit any signs of toxicity in SD rats and safe to be used on disease model

Keywords: Lauric acid, acute oral toxicity, haematological parameters, biochemical parameters.

\section{Introduction}


60 Plant-based products are considered as the primary source for food additives and ingredients

61 in various natural products. Natural substances are added in the food to enhance its flavour,

62 taste and appearance. Various plant additives are being used for centuries to preserve various

63 health care products and supplements (Amen et al. 2019; Arya et al. 2012a). According to the

64 world health organization (WHO) recommendation, food additives must pass through the

65 safety screen prior to use in any products. Additives in the form of crude plant or extracts are

66 needed to ensure processed food remains safe, and in good condition, a variety of plants

67 extracts contain specific phytochemicals whose biological activities is not known. Possibly,

68 some unwanted phytocompounds might lead to toxic effects or effects products preserving

69 capacity, stability and even the nutritional value of the products (Organization 2015; Yakob et

70 al. 2012). However, chemical characterization, proper dosing regimen, and insufficient

71 knowledge of the toxicity data constraint limit the usage of additives and herbal medicine

72 (Deng et al. 2013). Thus, it is the current need to evaluate the possible toxicity of the plant

73 extract and phytocompounds before its therapeutic use.

74 Lauric acid (LA) is the primary (> 50\%) composition of coconut oil (Sheela et al. 2016). It is 75 a medium-chain fatty acid (MCFA) found abundantly in the coconut oil, palm kernel oil and 76 laurel oil, which constitutes about half of the fatty acid (Beare-Rogers et al. 2001; Ubgogu et 77 al. 2006). It is also found in various kinds of foods, such as fruits, seeds, and breast milk (Alves 78 et al. 2017; Silberstein et al. 2013; Uday Kumar 2014). It possesses pleiotropic biological 79 activities, including potent anti-microbial effects (Dayrit 2015), beneficial effect on the 80 cardiovascular system (CVS) by increasing high-density lipoproteins (HDL) and reducing 81 blood pressure and heart rate in hypertensive rats (Ahola et al. 2017). Moreover, it also prevents 
82 testosterone-induced prostatic hyperplasia (Babu et al. 2010), and promote apoptosis in breast

83 and cancerous endometrial cells (Lappano et al. 2017).

84 Despite various pharmacological properties, scientific evidence on LA's toxicological, and 85 safety profile is not available. This is the first study aimed to investigate the acute toxicity of 86 LA following the Organization of Economic Cooperation and Development (OECD 423) 87 guideline in female Sprague Dawley (SD) rats with slight modifications. In this study, we 88 evaluated numerous parameters, like body weight, food and water intake, haematology, 89 biochemistry, and the histopathological changes in various tissues as shown in Figure 1.

\section{2.Materials \& Methods}

\subsection{Ethical Consideration}

92 The acute toxicity study of LA was accomplished in accordance with the guidelines stipulated by 93 the Institutional Animal Care and Use Committee (IACUC), Faculty of Medicine, University of 94 Malaya, Kuala Lumpur, Malaysia with animal ethics approval no: 2018-210605/TAY/R/AA 95 (2018295).

\subsection{Reagents}

97 Lauric acid (MKCF8837, purity more than 98 \%) Sigma-Aldrich (St Louis, MO 63103 USA 31498 77-5765), Tween-20 (C01-TW121-00, Systerm, UK), normal saline 0.9\% (B Braun),10\% neutral 99 buffered formalin solution pH 7.4 (R\&M, UK), Haematoxylin (Merck, USA) and Eosin (Systerm, 100 UK), Masson trichrome (Abcam150686), Periodic Acid Schiff (Abcam150680) and Picro Sirius 101 Red stain kit (Abcam 150681).

102 All other chemicals and solvents were of analytical grade.

103 2.3. Experimental animals 
104 In this study, eighteen (18) healthy specific pathogens-free (SPF) female SD rats, weighing 240-

105250 gram (g), age 8-10 weeks old were procured from the Animal Experimental Unit (AEU),

106 Faculty of Medicine, University of Malaya. The AEU facility at the University of Malaya is

107 certified by the Association for Assessment and Accreditation of Laboratory Animal Care

108 International (AAALAC International). All the animals were randomly segregated in three

109 different groups (six animals in each group) and housed in polypropylene cages for seven days to

110 acclimatise laboratory environment prior to the experiments. A consistent environment of 12-hour

111 light/dark cycle, temperature $22 \pm 2{ }^{\circ} \mathrm{C}$, and humidity of $50 \pm 10 \%$ were maintained. The animals

112 were allowed a standard rodent pellet diet and reverse osmosis (RO) water ad libitum throughout

113 the experimental period.

114 2.4. Acute oral toxicity test

115 Acute toxicity study was conducted to assess whether LA produce any mortality or other adverse

116 reactions upon oral administration of dose (300 and $2000 \mathrm{mg} / \mathrm{kg}$ body weight), according to

117 guideline 423 provided by the OECD for the acute toxicity class method procedure (OECD

118 2001)with minor amendments (Co-operation \& Development 2002). Before the experiment, all

119 the animals were carefully weighed, marked, and grouped accordingly:

120 Group I ( $\mathrm{n}=6)$ : Vehicle (Tween 20/normal saline)-treated

121 Group II ( $\mathrm{n}=6)$ : Lauric acid-treated, dose $300 \mathrm{mg} / \mathrm{kg}$ body weight

122 Group III ( $\mathrm{n}=6)$ : Lauric acid-treated, dose $2000 \mathrm{mg} / \mathrm{kg}$ body weight.

123 The LA was dissolved in Tween 20 and diluted with normal saline $0.9 \%$ to get the desired dose

124 (Alves et al. 2017). Animals fasted overnight before dosing, and treatment groups received freshly

125 prepared single doses of LA suspension at 300 and $2000 \mathrm{mg} / \mathrm{kg}$ body weight, while animals in the

126 control group received Tween 20 or normal saline $0.9 \%$ suspension equally based on individual 
127 body weight. Each gavage volume was $10 \mathrm{~mL} / \mathrm{kg}$ body weight. All efforts were made to lessen

128 experimental animals' suffering, especially in handling and oral gavage.

129 2.5. Daily observations

130 After oral gavage, diet was withheld except water for 2-3 hours while animals were monitored 131 individually with special attention in the first half-hour till completion of first 24 hours followed 132 by daily cage-side examination for fourteen days for any signs of toxicity including general 133 behavioural in skin, eyes, touch, activeness, and movement changes. All the changes observed

134 were well documented before and after the gavage.

\section{2.6. Body weight, food, and water consumption}

136 The body weight of the individual animal was carefully noted before and after oral administration 137 of the LA or vehicle, then weekly and lastly on day fifteen (euthanized day). Daily food (g/day), 138 and water ( $\mathrm{ml} /$ day) intake was noted on daily basis in all the three groups for fourteen days.

\section{2.7. Haematology and biochemical analysis}

140 On day fourteen, all the animals fasted overnight for 12 hours, only water was allowed. All the 141 animals were euthanized in the morning by an intraperitoneal (IP) injection of ketamine $(80 \mathrm{mg} / \mathrm{kg}$ )

$142 \&$ xylazine $(7 \mathrm{mg} / \mathrm{kg})$, and blood was collected via micro-capillary tubes from the retro-orbital 143 plexus region into two different sets of test tubes, one containing anticoagulant, ethylene 144 diaminotetraacetic acid (EDTA) for haematological tests including red blood cells (RBC), white 145 blood cells (WBC), platelets count, haemoglobin (Hb), packed cell volumes (PCV), mean 146 corpuscular volume (MCV), mean corpuscular haemoglobin $(\mathrm{MCH})$, mean corpuscular 147 haemoglobin concentration (MCHC), neutrophil, lymphocytes, monocytes, and eosinophils and 148 the other without additives for clinical biochemistry tests like urea, creatinine, calcium, inorganic 149 phosphate, uric acid, sodium, potassium, chloride, total cholesterol (TC), high-density lipoproteins 
150 (HDL), low-density lipoproteins (LDL), triglycerides (TG), total (HDL) ratio, albumin, globulin,

151 albumin-globulin $(\mathrm{A} / \mathrm{G})$ ratio, ALP, AST and ALT levels. The collected blood samples were then

152 sent to an ISO-certified blood-testing laboratory.

153 2.8. Measurement of relative organ weight

154 Internal organs such as adrenal glands, brain, eyes, heart, kidneys, liver, lungs, ovaries, spleen,

155 stomach, urinary bladder, uterus, and cervix/vagina were isolated through a fine incision in the

156 abdomen at the midline of the euthanized animals. All the harvested tissues were cleaned with

157 phosphate buffer saline (PBS), wiped with clean blotting paper and weighed on a calibrated

158 weighing balance. Relative organ weight (ROW) of all the animals was noted in proportion to

159 body weight according to the following equation:

160

$\mathrm{ROW}=\frac{\text { absolute organ weight }}{\text { body weight at the time of sacrifice }} X 100$

161

162

\subsection{Histopathological analysis}

163 Histopathological examination was conducted on the harvested liver, kidney, heart, lungs, brain,

164 spleen, and pancreas in all the animals. Tissues were preserved in $10 \%$ neutral, buffered formalin 165 solution for 48 hours at $4{ }^{\circ} \mathrm{C}$ for histopathological study. Paraffin-embedded specimens of selected tissues were cut into 4-5 $\mu \mathrm{m}$ thick samples and stained with haematoxylin and eosin (H\&E), Masson trichrome, Periodic Acid Schiff (PAS) and Picro Sirius Red staining as per the manufacturer protocol detailed in the kits. Later, all the stained tissues were sectioned and observed under the fluorescence compound microscope (40X) (Eclipse Ni-U, Nikon Corporation, Japan).

\subsection{Statistical analysis}

171 All statistical results were expressed as the mean \pm standard deviation (SD). The comparison 172 between the treated and control group was performed by a one-way analysis of variance (ANOVA) 
173 using statistical software, SPSS package version 22 (IBM, SPSS Statistics, Inc., Chicago, IL, USA)

174 to evaluate the significant differences. The $(\mathrm{p}<0.05)$ compared to the control group was 175 considered statistically significant.

\section{$176 \quad 3$. Results}

177 3.1. Acute toxicological evaluation and daily observation

178 Animals in LA (300 and $2000 \mathrm{mg} / \mathrm{kg}$ body weight) treated group were normal and healthy during 179 fourteen days study period. No signs of mortality or sudden death were observed compared to the 180 untreated group animals. No significant changes in the temperature, skin, eye colour, food and 181 water intake were observed. Furthermore, no behavioural changes or signs of diarrhoea, coma, 182 sedation and tremors were noted as compared to the control group (Table 1). Experimental results 183 suggest that $\mathrm{LD}_{50}$ of LA should be higher than $2000 \mathrm{mg} / \mathrm{kg}$ body weight.

\subsection{Effect of LA on body weight, food and water consumption}

Body weight, food \& water intake in the LA treated groups (300 and $2000 \mathrm{mg} / \mathrm{kg}$ body weight) were noted to be non-significant compared to the control group. However, LA treated groups showed slight changes in the body weight, food and water consumption on day fourteen, compared was noted as $244.71 \pm 3.13 \mathrm{~g}$, whereas treatment groups showed $247.53 \pm 2.96$, and $240.63 \pm 4.76$ $0.064 \mathrm{~g}$, while LA treated animals ( 300 and $2000 \mathrm{mg} / \mathrm{kg}$ body weight) displayed non-significant gain in the body weight $(14.93 \pm 0.68$ and $15.36 \pm 0.76 \mathrm{~g})$, respectively. The percentage mean in the body weight of all the treated animals was non-significant in comparison to the control group $(p>0.05)$, as shown in Table 2. 
196 Moreover, LA administration (300 and $2000 \mathrm{mg} / \mathrm{kg})$ showed non-significant changes $(p>0.05)$

197 in the food and water consumption, compared to the control group, as shown in Table 3.

198 3.3. Effect of LA on relative organ weight.

199 The relative organ weight of the harvested tissues - adrenal glands, brain, eyes, heart, kidney, liver,

200 lungs, ovaries, spleen, stomach, urinary bladder, uterus and cervix/vagina, revealed non-significant

201 changes post-LA treatment (300 and $2000 \mathrm{mg} / \mathrm{kg}$ body weight) compared with the control group

202 animals $(p>0.05)$, as shown in Table 4.

203 3.4. Effect of LA on haematology and clinical biochemistry

204 The effect on haematological analysis is summarised in Table 5. Parameters including RBC,

205 WBC, platelets count, Hb, PCV, MCV, MCH, MCHC, neutrophil, lymphocytes, monocytes, and 206 eosinophils shows non-significant changes $(p>0.05)$ after oral administration of LA (300 and $2072000 \mathrm{mg} / \mathrm{kg}$ body weight) when compared with the control animals. Importantly, all the values 208 were within the reference range, compared to the control group.

209 Similarly, the biochemical analysis of liver and renal function tests, including urea, creatinine, 210 calcium, inorganic phosphate, uric acid, sodium, potassium, chloride, TC, HDL, LDL, TG, total 211 HDL ratio, albumin, globulin, A/G ratio, ALP, AST and ALT levels for LA treatment groups were 212 not affected and observed to be normal (non-significant $(p>0.05)$ ), when compared with the 213 control group as presented in Table 6.

214 3.5. Effects of LA on Histopathology of internal organs

215 The histopathological analysis involves macroscopic and microscopic examination of processed 216 and fixed tissues to visualise various components and structural alterations in the tissues (Greaves 217 2011; Khoo et al. 2018). H\&E staining is the most common and widely used technique to 218 essentially identify morphological changes during diagnosis and screening of any malignancies in 
219 the tissues (Fischer et al. 2008). However, Masson trichrome staining remains reliable for the 220 cytoplasm, which gives in-depth and selective detail about the connective tissue (Tsounapi et al. 221 2017). PAS staining assesses the changes in glycogen content within muscle fibre sections (Arya 222 et al. 2015; Fairchild \& Fournier 2004). Moreover, the collagen content is analysed with the help 223 of Picro Sirius Red staining, which provides a clear understanding of collagen accumulation in 224 the tissues (Lattouf et al. 2014).

225 In brief, macroscopic analysis of liver sections (Figure 2) in LA-treated rats (300 and $2000 \mathrm{mg} / \mathrm{kg}$ 226 body weight) displays no alterations in the colour or texture, importantly no changes to 227 hepatocytes, hepatic sinusoids, central vein, and portal triad were observed when compared with 228 the control group (Figure 3). Kidney showed no structural degeneration, and colour changes in 229 the renal cortex and tubules, without any tubular necrosis and inflammation in LA-treated animals 230 compared to untreated animals, as displayed (Figure 4 and 5). The photomicrographs of the heart 231 (Figure 6 and 7) tissue showed a normal size of myocardial fibre and filaments when compared 232 with the control group. Lung tissues (Figure 8 and 9) appeared to be normal, with no abnormal 233 changes noted in colour. Moreover, microscopic observation displayed thin inter-alveolar septa, 234 clear alveoli and alveolar sacs with the absence of inflammatory cells, including neutrophils, or 235 thickening of alveolar septa, when compared with the untreated group. Furthermore, brain (Figure $236 \mathbf{1 0}$ and 11) tissues showed normal morphology with the regular shape of the pyramidal neuron and 237 uniform distribution of glial cells in LA-treated and control animals. Macroscopic texture (Figure 12 and 13) exhibited normal and regular appearance with white and red pulp without any sign of 239 apoptotic, necrotic lesions or megakaryocytosis compared with the control group. Microscopic 240 appearance of the pancreas (Figure 14 and 15) appeared with healthy acinar, clear round or oval241 shaped Islets cells in cluster form, with lightly stained cytoplasm in the LA-treatment and control 
242 animals. Thus, the study results suggest that treatment with minimum and maximum doses of LA

243 (300 \& $2000 \mathrm{mg} / \mathrm{kg}$ body weight) did not cause any tissue damage or morphological alteration at

244 the cellular level.

\subsection{Discussion}

246 Toxicological studies of plant-based ingredients or food additives are important to ensure

247 processed food remains safe and in good condition throughout its preservation to avoid any disease

248 conditions. Herbs or plants additives used in dietary supplements, nutraceuticals, should be

249 investigated for toxicity, despite their traditional claims (Figueredo et al. 2018; Lulekal et al.

250 2013).

251 Lauric acid revealed various pharmacological activities, but its safety profile still remains

252 unevaluated. The current study is undertaken to screen the safety, and toxicity of LA at two

253 different dose levels in normal rats, following OECD 423 guidelines.

254 No morbidity or mortality was noticed in LA-treated animals throughout fourteen days of the 255 experimental period. Moreover, in line with previous study of (Arya et al. 2012b), no changes 256 were observed in general behaviour of treated animals when compared with the control group, 257 suggesting that oral ingestion of LA neither cause any alterations nor produced any internal 258 changes in female SD rats with doses up to $2000 \mathrm{mg} / \mathrm{kg}$ body weight.

259 Body weight changes are the basic parameter which indicates the health status of animals. 260 However, abrupt variations in the body weight indicate the toxic nature of the chemicals or drugs 261 (Dongmo et al. 2019). In this study, LA treatment and control group recorded a normal gain in 262 body weight, indicating, LA does not cause any physiological alterations that affects the normal 263 growth in the animals, which is in agreement with the previous study published by (Clemente et 264 al. 2019). Similarly, organ weight variation is the fundamental and perceptive factor correlating 
265 organ to body weight index, which is important and critical in determining drug toxicity linked to 266 treatment-related effects (Sellers et al. 2007). It is believed that medicinal plants in high dose could 267 cause toxic or even lethal effects when administered in vivo (Silveira et al. 2008; Siwe et al. 2015). 268 Results from this study showed no difference in ROW in the treatment group when compared to 269 control group, which indicates that LA is safer to the internal organs, supported by an earlier study 270 published by (Porwal et al. 2017). Studies have proven that ingesting toxic substances could 271 suppress appetite, thus leading to less caloric intake (Madingou et al. 2016). During fourteen days 272 observation period, no significant changes were noted in water and food consumption (Table 5), 273 which shows that LA has no effect on the appetite of the animals, which is in line with the previous 274 findings published by (de Oliveira et al. 2020; Tonholo et al. 2020).

275 The haematopoietic system is crucial in the production of blood cells that accelerate metabolic 276 functions and enhance normal proliferation in the living organism which act and delineate as a 277 vital tool. This system is profound and directly or indirectly susceptible to chemical-induced 278 injury, affecting physiological and pathological status in both humans and animals (da Silva et al. 279 2018; Traesel et al. 2014). In the current findings, LA administration indicate non-significant 280 changes in the essential blood cells and related parameters RBC, WBC, platelets count, $\mathrm{Hb}$ PCV, 281 Mean MCV, MCH, MCHC, Neutrophil, Lymphocyte, Monocytes and Eosinophils, suggesting 282 non-toxic nature of LA on haematological parameters and substantiating an understanding of 283 normal haematopoiesis, which is in line with the previous findings published by (Deyno et al. 284 2020; Thai et al. 2020).

285 The liver is the central metabolic organ playing a key role in body metabolic functions where drug 286 and chemical metabolism, biotransformation and detoxification occurs (Doherty 2016). When 287 hepatic cellular damage occurs due to hepatotoxic substances, the sensitive markers including 
288 transaminase serum enzymes ALT \& AST start releasing from the cytosol and translocate into the

289 bloodstream, leading to mild or severe liver injury (Figueredo et al. 2018; Hazarika et al. 2019;

290 Ramaiah 2011). In our study, LA did not elevate these transaminase enzymes, considering non-

291 toxic nature of LA at different dose levels. Similar findings were noted by (Moorthy et al. 2019),

292 where oral administration of the geraniin-enriched extract at $2000 \mathrm{mg} / \mathrm{kg}$ body weight did not

293 affect the biochemical parameters. Similarly, LA treatment did not change renal functions

294 including serum creatinine and urea levels, which are used as an essential index to estimate renal

295 damage (Arya et al. 2014; Mariappan et al. 2011; Meguellati et al. 2019). The elevated level of

296 creatinine and urea in the blood displays malfunctioning of the kidney (Brondani et al. 2017;

297 Feriani et al. 2017; Kifayatullah et al. 2015). In addition, serum electrolyte levels of LA treated

298 animals observed to be in normal ranges. Overall, biochemical parameters are in line with previous

299 reports of (Bedi \& Krishan 2019; Thinkratok et al. 2014).

300 Histopathological investigation plays a significant role in determining tissue morphology through

301 microscopical evaluations. The analysis of internal organs are identical and consider as the prime

302 safety tool to determine any histological perturbations or deformities in the tissues (Chitra et al.

303 2015; Prabu et al. 2013). Therefore, the histopathological judgements concrete the haematological

304 and biochemical findings and further substantiate the biological response factors (Jaganathan et al.

305 2012). Histopathological examination (macroscopic and microscopic) of internal organs including

306 liver, kidney, heart, lungs, brain, spleen, and pancreas revealed a regular architecture, no

307 morphological alterations were observed in LA treatment groups compared to the control group.

308 Tissue degeneration or anomalies leading to necrosis, apoptosis or fibrosis are the basic parameters

309 to determine toxicity in internal organs (de Lima et al. 2017). 
310 The liver is the metabolic connective tissue which controls biliary and vascular traffic.

311 Administration of LA at the minimum and maximum dose did not cause structural degeneration

312 or accumulation in the liver tissues, displaying normal clusters of hepatocytes and parenchymal

313 cells housed in cord-like arrangements. In this study, microscopical features of liver tissue is in

314 agreement with the published data by (Khoo et al. 2018) who postulated that changes to these

315 cellular events might potentially be associated with the accumulation of exogenous chemicals and

316 their metabolites may cause dose-dependent toxicity or damage to the liver (Debelo et al. 2016).

317 Similarly, LA administration did not alter kidney tissue, which showed organised pyramidal

318 structure without any tubular necrosis and inflammation in the cortex and inner portion of the

319 medulla region. However, the toxic effect of any compound on the kidney is demonstrated by

320 changes in the serum creatinine or urea level (Gopi et al. 2016). Finding from this study reveals

321 the harmless nature of LA on renal function by establishing the outcomes from histopathological

322 analysis, which did not notice lesion or necrotic marks upon LA administration. Likewise, LA

323 treatment on heart tissues displayed normal architecture of myocardial fibre and filaments which

324 is in line with (Greaves 2011) findings, who reported no morphological changes in heart tissues

325 upon treatment with the phytocompounds. In a similar way, lungs of LA-treated animals showed

326 no treatment-related morphological alterations, and our findings are in agreement with (Aamir et

327 al. 2019) who reported that no toxicological alteration was noted upon Arjunolic acid treatment in

328 normal female SD rats. Furthermore, brain tissues showed normal morphology upon LA treatment,

329 with no alterations to the cell types approaching through normal characteristics based on tissue

330 pattern recognition, including neurons, glia, and microglia cells without any modulation to

331 perivascular region. Thus, our study is supported by previous findings by (Pravallika et al. 2019)

332 who reported no structural and morphological changes in brain tissues following treatment with 
333 ethanolic extract of Centella asiatica plant. Moreover, LA treatment did not alter pancreas and

334 spleen tissue which shows normal architecture, as we know rodent pancreas and spleen are diffused

335 and soft compare to human tissues, which is in line with the previously published study by (Prabu

336 et al. 2013) that reveals no morphological variation in tissues of control and hydroalcoholic extract

337 of polyherbal treatment groups.

338 The present study expressed that oral administration of LA did not cause any morbidity or 339 mortality at the selected doses, and LD50 values were greater than $2000 \mathrm{mg} / \mathrm{kg}$ body weight. Based

340 on the current findings, LA should remain in toxicity class 5 , which exhibited the lowest toxicity

341 (LD50 $>2000 \mathrm{mg} / \mathrm{kg}$ body weight) as per the OECD 423 guideline, under chemical labelling and

342 classification (OECD 2001).

343 4.Conclusions

344 The findings of the current study showed that LA did not cause any significant changes upon oral

345 administration of LA up to $2000 \mathrm{mg} / \mathrm{kg}$ body weight in female SD rats, no treatment-related signs

346 of toxicity or mortality were noted. Moreover, histopathological examination exhibits no

347 remarkable changes in the harvested tissues. Thus, it provides basic information on the toxicity

348 and safety profile of LA, indicating low toxicity in the analysed parameters. This study could be

349 helpful in the selection of dosages for future subacute or chronic disease model. However, in

350 future, well-designed treatment strategies on pharmacological aspects should be carried out to set

351 a clear understanding of safety and efficacy. Therefore, further validation on LA would enable to

352 decide effective therapeutic dose prior to its long-term treatment as well as before the development

353 of any health care products.

354

355 
356

357

358

359

360

361

362

363

364

365

366

367

368

369

370

371

372

373

374

375

376

377

378

379

380

381

382

383

384

385

386

387

388

389

390

391

392

393

394

\section{Acknowledgements}

The current study is funded by Taylor's University Flagship Research Grant (TUFR/2017/002/01)

under the theme "Ageing and Quality of Life". We are thankful to the University of Malaya for

providing animal facilities.

\section{References}

Aamir K, Khan HU, Hossain CF, Afrin MR, Shaik I, Salleh N, Giribabu N, and Arya A. 2019. Oral toxicity of arjunolic acid on hematological, biochemical and histopathological investigations in female Sprague Dawley rats. PeerJ 7:e8045.

Ahola AJ, Lassenius MI, Forsblom C, Harjutsalo V, Lehto M, and Groop P-H. 2017. Dietary patterns reflecting healthy food choices are associated with lower serum LPS activity. Scientific Reports 7:6511.

Alves NFB, de Queiroz TM, de Almeida Travassos R, Magnani M, and de Andrade Braga V. 2017. Acute treatment with lauric acid reduces blood pressure and oxidative stress in spontaneously hypertensive rats. Basic \& clinical pharmacology \& toxicology 120:348353.

Amen OM, Sarker SD, Ghildyal R, and Arya A. 2019. Endoplasmic reticulum stress activates unfolded protein response signaling and mediates inflammation, obesity, and cardiac dysfunction: therapeutic and molecular approach. Frontiers in pharmacology 10.

Arya A, Achoui M, Cheah S-C, Abdelwahab SI, Narrima P, Mohan S, Mustafa MR, and Mohd MA. 2012a. Chloroform fraction of Centratherum anthelminticum (L.) seed inhibits tumor necrosis factor alpha and exhibits pleotropic bioactivities: Inhibitory role in human tumor cells. Evidence-based complementary and alternative medicine 2012.

Arya A, Al-Obaidi MMJ, Karim RB, Taha H, Khan AK, Shahid N, Sayem AS, Looi CY, Mustafa MR, and Mohd MA. 2015. Extract of Woodfordia fruticosa flowers ameliorates hyperglycemia, oxidative stress and improves $\beta$-cell function in streptozotocin-nicotinamide induced diabetic rats. Journal of ethnopharmacology 175:229-240.

Arya A, Al-Obaidi MMJ, Shahid N, Noordin MIB, Looi CY, Wong WF, Khaing SL, and Mustafa MR. 2014. Synergistic effect of quercetin and quinic acid by alleviating structural degeneration in the liver, kidney and pancreas tissues of STZ-induced diabetic rats: a mechanistic study. Food and chemical toxicology 71:183-196.

Arya A, Cheah SC, Looi CY, Taha H, Mustafa MR, and Mohd MA. 2012b. The methanolic fraction of Centratherum anthelminticum seed downregulates pro-inflammatory cytokines, oxidative stress, and hyperglycemia in STZ-nicotinamide-induced type 2 diabetic rats. Food and chemical toxicology 50:4209-4220.

Babu SV, Veeresh B, Patil AA, and Warke Y. 2010. Lauric acid and myristic acid prevent testosterone induced prostatic hyperplasia in rats. European journal of pharmacology 626:262-265. 
395

396

397

398

399

400

401

402

403

404

405

406

407

408

409

410

411

412

413

414

415

416

417

418

419

420

421

422

423

424

425

426

427

428

429

430

431

432

433

434

435

436

Beare-Rogers J, Dieffenbacher A, and Holm J. 2001. Lexicon of lipid nutrition (IUPAC Technical Report). Pure and Applied Chemistry 73:685-744.

Bedi O, and Krishan P. 2019. Investigations on acute oral toxicity studies of purpurin by application of OECD guideline 423 in rodents. Naunyn-Schmiedeberg's archives of pharmacology:1-7.

Brondani JC, Reginato FZ, da Silva Brum E, de Souza Vencato M, Lhamas CL, Viana C, da Rocha MIUM, de Freitas Bauermann L, and Manfron MP. 2017. Evaluation of acute and subacute toxicity of hydroethanolic extract of Dolichandra unguis-cati L. leaves in rats. Journal of ethnopharmacology 202:147-153.

Chitra B, Ramaswamy R, and Suba V. 2015. Toxicity evaluation of Pũrna Cantirotaya Centũram, a Siddha medicine in Wistar rats. International scholarly research notices 2015.

Clemente M, Miguel M, Felipe K, Gribner C, Moura P, Rigoni A, Fernandes L, Carvalho J, Hartmann I, and Piltz M. 2019. Acute and sub-acute oral toxicity studies of standardized extract of Nasturtium officinale in Wistar rats. Regulatory Toxicology and Pharmacology 108:104443.

Co-operation OfE, and Development. 2002. Test No. 423: Acute oral toxicity-Acute toxic class method: OECD Publishing.

da Silva ARH, Lopes LQS, Cassanego GB, de Jesus PR, Figueredo KC, Santos RCV, Lopes GHH, and de Freitas Bauermann L. 2018. Acute toxicity and antimicrobial activity of leaf tincture Baccharis trimera (Less). biomedical journal 41:194-201.

Dayrit FM. 2015. The properties of lauric acid and their significance in coconut oil. Journal of the American Oil Chemists' Society 92:1-15.

de Lima FF, Traesel GK, Menegati SELT, dos Santos AC, Souza RIC, de Oliveira VS, SanjinezArgandoña EJ, Cardoso CAL, Oesterreich SA, and do Carmo Vieira M. 2017. Acute and subacute oral toxicity assessment of the oil extracted from Attalea phalerata Mart ex Spreng. pulp fruit in rats. Food research international 91:11-17.

de Oliveira NA, Sandini TM, Cornelio-Santiago HP, Martinelli ECL, Raspantini LER, Raspantini PC, Momo C, de Oliveira AL, and Fukumasu H. 2020. Acute and subacute (28 days) toxicity of green coffee oil enriched with diterpenes cafestol and kahweol in rats. Regulatory Toxicology and Pharmacology 110:104517.

Debelo N, Afework M, Debella A, Makonnen E, Ergete W, and Geleta B. 2016. Assessment of hematological, biochemical and histopathological effects of acute and sub-chronic administration of the aqueous leaves extract of thymus schimperi in rats. Journal of Clinical Toxicology 6:2161-0495.

Deng Y-x, Cao M, Shi D-x, Yin Z-q, Jia R-y, Xu J, Wang C, Lv C, Liang X-x, and He C-I. 2013. Toxicological evaluation of neem (Azadirachta indica) oil: acute and subacute toxicity. Environmental toxicology and pharmacology 35:240-246.

Deyno S, Abebe A, Tola MA, Hymete A, Bazira J, Makonnen E, and Alele PE. 2020. Acute and subacute toxicity of Echinops kebericho decoction in rats. BMC Complementary Medicine and Therapies 20:2.

Doherty DG. 2016. Immunity, tolerance and autoimmunity in the liver: A comprehensive review. Journal of autoimmunity 66:60-75.

Peer) reviewing PDF | (2019:11:43420:1:2:NEW 12 Feb 2020) 
437 Dongmo OLM, Epoh NJ, Tadjoua HT, Yousuf S, Telefo PB, Tapondjou LA, and Choudhary MI. 2019.

438

439

440

441

442

443

444

445

446

447

448

449

450

451

452

453

454

455

456

457

458

459

460

461

462

463

464

465

466

467

468

469

470

471

472

473

474

475

476

477

478

479

480 Acute and sub-acute toxicity of the aqueous extract from the stem bark of Tetrapleura tetrapteura Taub.(Fabaceae) in mice and rats. Journal of ethnopharmacology 236:42-49.

Fairchild TJ, and Fournier PA. 2004. Glycogen determination using periodic acid-schiff: artifact of muscle preparation. Medicine and science in sports and exercise 36:2053-2058.

Feriani A, del Mar Contreras M, Talhaoui N, Gómez-Caravaca AM, Taamalli A, Segura-Carretero A, Ghazouani L, El Feki A, and Allagui MS. 2017. Protective effect of Globularia alypum leaves against deltamethrin-induced nephrotoxicity in rats and determination of its bioactive compounds using high-performance liquid chromatography coupled with electrospray ionization tandem quadrupole-time-of-flight mass spectrometry. Journal of functional foods 32:139-148.

Figueredo KC, Guex CG, Reginato FZ, da Silva ARH, Cassanego GB, Lhamas CL, Boligon AA, Lopes $\mathrm{GHH}$, and de Freitas Bauermann L. 2018. Safety assessment of Morus nigra L. leaves: Acute and subacute oral toxicity studies in Wistar rats. Journal of ethnopharmacology 224:290-296.

Fischer AH, Jacobson KA, Rose J, and Zeller R. 2008. Hematoxylin and eosin staining of tissue and cell sections. Cold Spring Harbor Protocols 2008:pdb. prot4986.

Gopi S, Jacob J, and Mathur KY. 2016. Acute and subchronic oral toxicity studies of hydrogenated curcuminoid formulation 'CuroWhite' in rats. Toxicology reports 3:817-825.

Greaves P. 2011. Histopathology of preclinical toxicity studies: interpretation and relevance in drug safety evaluation: Academic Press.

Hazarika I, Geetha K, Sundari PS, and Madhu D. 2019. Acute oral toxicity evaluation of extracts of Hydrocotyle sibthorpioides in wister albino rats as per OECD 425 TG. Toxicology reports 6:321-328.

Jaganathan R, Ravinayagam V, Panchanadham S, and Palanivelu S. 2012. Troxicological, biochemical and histopathological evaluation of Tridham, a siddha medicine in Wistar albino rats. Journal of Biochemical Technology 4.

Khoo L, Foong Kow A, Maulidiani M, Lee M, Tan C, Shaari K, Tham C, and Abas F. 2018. Hematological, Biochemical, Histopathological and $1 \mathrm{H}-\mathrm{NMR}$ Metabolomics Application in Acute Toxicity Evaluation of Clinacanthus nutans Water Leaf Extract. Molecules 23:2172.

Kifayatullah M, Mustafa MS, Sengupta P, Sarker MMR, Das A, and Das SK. 2015. Evaluation of the acute and sub-acute toxicity of the ethanolic extract of Pericampylus glaucus (Lam.) Merr. in BALB/c mice. Journal of Acute Disease 4:309-315.

Lappano R, Sebastiani A, Cirillo F, Rigiracciolo DC, Galli GR, Curcio R, Malaguarnera R, Belfiore A, Cappello AR, and Maggiolini M. 2017. The lauric acid-activated signaling prompts apoptosis in cancer cells. Cell death discovery 3:17063.

Lattouf R, Younes R, Lutomski D, Naaman N, Godeau G, Senni K, and Changotade S. 2014. Picrosirius red staining: a useful tool to appraise collagen networks in normal and pathological tissues. Journal of Histochemistry \& Cytochemistry 62:751-758.

Lulekal E, Asfaw Z, Kelbessa E, and Van Damme P. 2013. Ethnomedicinal study of plants used for human ailments in Ankober District, North Shewa Zone, Amhara region, Ethiopia. Journal of Ethnobiology and Ethnomedicine 9:63.

Madingou NOK, Traore A, Souza A, Mounanga MMB, Samseny RRA, Ouedraogo S, and Traore AS. 2016. Preliminary studies of acute and sub-chronic toxicity of the aqueous extract of

Peer) reviewing PDF | (2019:11:43420:1:2:NEW 12 Feb 2020) 
481

482

483

484

485

486

487

488

489

490

491

492

493

494

495

496

497

498

499

500

501

502

503

504

505

506

507

508

509

510

511

512

513

514

515

516

517

518

519

520

521

522

523
Guibourtia tessmannii (Harms) J. Leonard stem barks (Caesalpiniaceae) in mice and rats. Asian Pacific Journal of Tropical Biomedicine 6:506-510.

Mariappan G, Saha B, Sutharson L, Singh A, Garg S, Pandey L, and Kumar D. 2011. Analgesic, antiinflammatory, antipyretic and toxicological evaluation of some newer 3-methyl pyrazolone derivatives. Saudi pharmaceutical journal 19:115-122.

Meguellati H, Ouafi S, Saad S, and Djemouai N. 2019. Evaluation of acute, subacute oral toxicity and wound healing activity of mother plant and callus of Teucrium polium L. subsp. geyrii Maire from Algeria. South African Journal of Botany 127:25-34.

Moorthy M, Khoo JJ, and Palanisamy UD. 2019. Acute oral toxicity of the ellagitannin geraniin and a geraniin-enriched extract from Nephelium lappaceum L rind in Sprague Dawley rats. Heliyon 5:e02333.

OECD TN. 2001. 423: Acute Oral toxicity-Acute Toxic Class Method. OECD Guidelines for the Testing of Chemicals, Section 4.

Organization WH. 2015. WHO guidelines on safety monitoring of herbal medicines in pharmacovigilance systems. 2004. Geneva: World Health Organization vii.

Porwal M, Khan N, and Maheshwari K. 2017. Evaluation of acute and subacute oral toxicity induced by ethanolic extract of Marsdenia tenacissima leaves in experimental rats. Scientia pharmaceutica 85:29.

Prabu P, Panchapakesan S, and Raj CD. 2013. Acute and sub-acute oral toxicity assessment of the hydroalcoholic extract of Withania somnifera roots in Wistar rats. Phytotherapy Research 27:1169-1178.

Pravallika PL, Mohan GK, Rao KV, and Shanker K. 2019. Biosynthesis, characterization and acute oral toxicity studies of synthesized iron oxide nanoparticles using ethanolic extract of Centella asiatica plant. Materials Letters 236:256-259.

Ramaiah SK. 2011. Preclinical safety assessment: current gaps, challenges, and approaches in identifying translatable biomarkers of drug-induced liver injury. Clinics in laboratory medicine 31:161-172.

Sellers RS, Mortan D, Michael B, Roome N, Johnson JK, Yano BL, Perry R, and Schafer K. 2007. Society of Toxicologic Pathology position paper: organ weight recommendations for toxicology studies. Toxicologic pathology 35:751-755.

Sheela DL, Nazeem PA, Narayanankutty A, Manalil JJ, and Raghavamenon AC. 2016. In silico and wet lab studies reveal the cholesterol lowering efficacy of lauric acid, a medium chain fat of coconut oil. Plant foods for human nutrition 71:410-415.

Silberstein T, Burg A, Blumenfeld J, Sheizaf B, Tzur T, and Saphier O. 2013. Saturated fatty acid composition of human milk in Israel: a comparison between Jewish and Bedouin women. The Israel Medical Association Journal: IMAJ 15:156-159.

Silveira PFd, Bandeira MAM, and Arrais PSD. 2008. Pharmacovigilance and adverse reactions to the medicinal plants and herbal drugs: a reality. Revista Brasileira de Farmacognosia 18:618-626.

Siwe GT, Enow-Orock GE, Amang AP, Mezui C, Dongmo AB, and Tan PV. 2015. Acute and subacute toxicological assessment of the leaf aqueous extract of Eremomastax speciosa (Acanthaceae) in wistar rats. Journal of Advances in Medical and Pharmaceutical Sciences 4:1-13.

Peer] reviewing PDF | (2019:11:43420:1:2:NEW 12 Feb 2020) 
524

525

526

527

528

529

530

531

532

533

534

535

536

537

538

539

540

541

542

543

544

545

546

547
Thai H, Nguyen CT, Thach LT, Tran MT, Mai HD, Nguyen TTT, Le GD, Van Can M, Dai Tran L, and Bach GL. 2020. Characterization of chitosan/alginate/lovastatin nanoparticles and investigation of their toxic effects in vitro and in vivo. Scientific Reports 10:1-15.

Thinkratok A, Suwannaprapha P, and Srisawat R. 2014. Safety assessment of hydroethanolic rambutan rind extract: acute and sub-chronic toxicity studies.

Tonholo D, Maltarollo V, Kronenberger T, Silva I, Azevedo P, Oliveira R, Souza L, and Tagliati C. 2020. Preclinical toxicity of innovative molecules: In vitro, in vivo and metabolism prediction. Chemico-biological interactions 315:108896.

Traesel GK, de Souza JC, de Barros AL, Souza MA, Schmitz WO, Muzzi RM, Oesterreich SA, and Arena AC. 2014. Acute and subacute ( 28 days) oral toxicity assessment of the oil extracted from Acrocomia aculeata pulp in rats. Food and chemical toxicology 74:320-325.

Tsounapi P, Honda M, Dimitriadis F, Kawamoto B, Hikita K, Muraoka K, Saito M, Sofikitis N, and Takenaka A. 2017. Impact of antioxidants on seminal vesicles function and fertilizing potential in diabetic rats. Asian journal of andrology 19:639.

Ubgogu O, Onyeagba R, and Chigbu O. 2006. Lauric acid content and inhibitory effect of palm kernel oil on two bacterial isolates and Candida albicans. African Journal of Biotechnology 5.

Uday Kumar D. 2014. Christopher V, Sobarani D, Nagendra Sastry Y (2014) Lauric Acid as Potential Natural Product in the Treatment of Cardiovascular Disease: A Review. J Bioanal Biomed 6:037-039.

Yakob HK, Uyub AM, and Sulaiman SF. 2012. Toxicological evaluation of $80 \%$ methanol extract of Ludwigia octovalvis (Jacq.) PH Raven leaves (Onagraceae) in BALB/c mice. Journal of ethnopharmacology 142:663-668. 


\section{Table 1 (on next page)}

The behavioural and general response of animals after oral administration of LA

( $n=$ normal, no=not observed $)$ 


\section{Table 1}

2 The behavioural and general response of animals after oral administration of LA

\begin{tabular}{lccc}
\hline Observation & Control & LA 300 mg/kg & LA 2000 mg/kg \\
\hline Temperature & n & n & n \\
Skin changes & no & no & no \\
Change eyes colour & no & no & no \\
General physique & n & n & n \\
Diarrhoea & no & no & no \\
Coma & no & no & no \\
Drowsiness & no & no & no \\
Breathing difficulty & no & no & no \\
Sedation & no & no & no \\
Tremor & no & no & no \\
Death & no & no & no
\end{tabular}

$3 \quad(\mathrm{n}=$ normal, no=not observed $)$

4 


\section{Table 2 (on next page)}

Effect of LA on body weight $(\mathrm{g})$ assessment

Values are expressed as the mean \pm standard deviation ( $n=6$ for each group, female). Oneway ANOVA $\left.{ }^{*} p<0.05\right)$ significant value 


\section{Table 2}

2 Effect of LA on body weight (g) assessment.

\begin{tabular}{lccccc}
\hline Week & Control & LA 300 $\mathbf{m g} / \mathbf{k g}$ & LA 2000 $\mathbf{~ m g} / \mathbf{k g}$ & F-value & P-value \\
\hline Day 0 & $244.71 \pm 3.13$ & $247.53 \pm 2.96$ & $240.63 \pm 4.76$ & 1.464 & 0.263 \\
Week 1\% & $7.64 \pm 0.46$ & $7.52 \pm 0.22$ & $7.87 \pm 0.35$ & 0.149 & 0.863 \\
Week 2\% & $14.81 \pm 0.064$ & $14.93 \pm 0.68$ & $15.36 \pm 0.76$ & 0.113 & 0.894
\end{tabular}

3 Values are expressed as the mean \pm standard deviation ( $\mathrm{n}=6$ for each group, female). One-way ANOVA

$\left.4 \quad{ }^{*} p<0.05\right)$ significant value

5 


\section{Table 3(on next page)}

Effect of LA on food and water consumption

Values are expressed as the mean \pm standard deviation ( $n=6$ for each group, female). Oneway $\left.\operatorname{ANOVA}^{*} p<0.05\right)$ significant value 


\section{Table 3}

2 Effect of LA on food and water consumption.

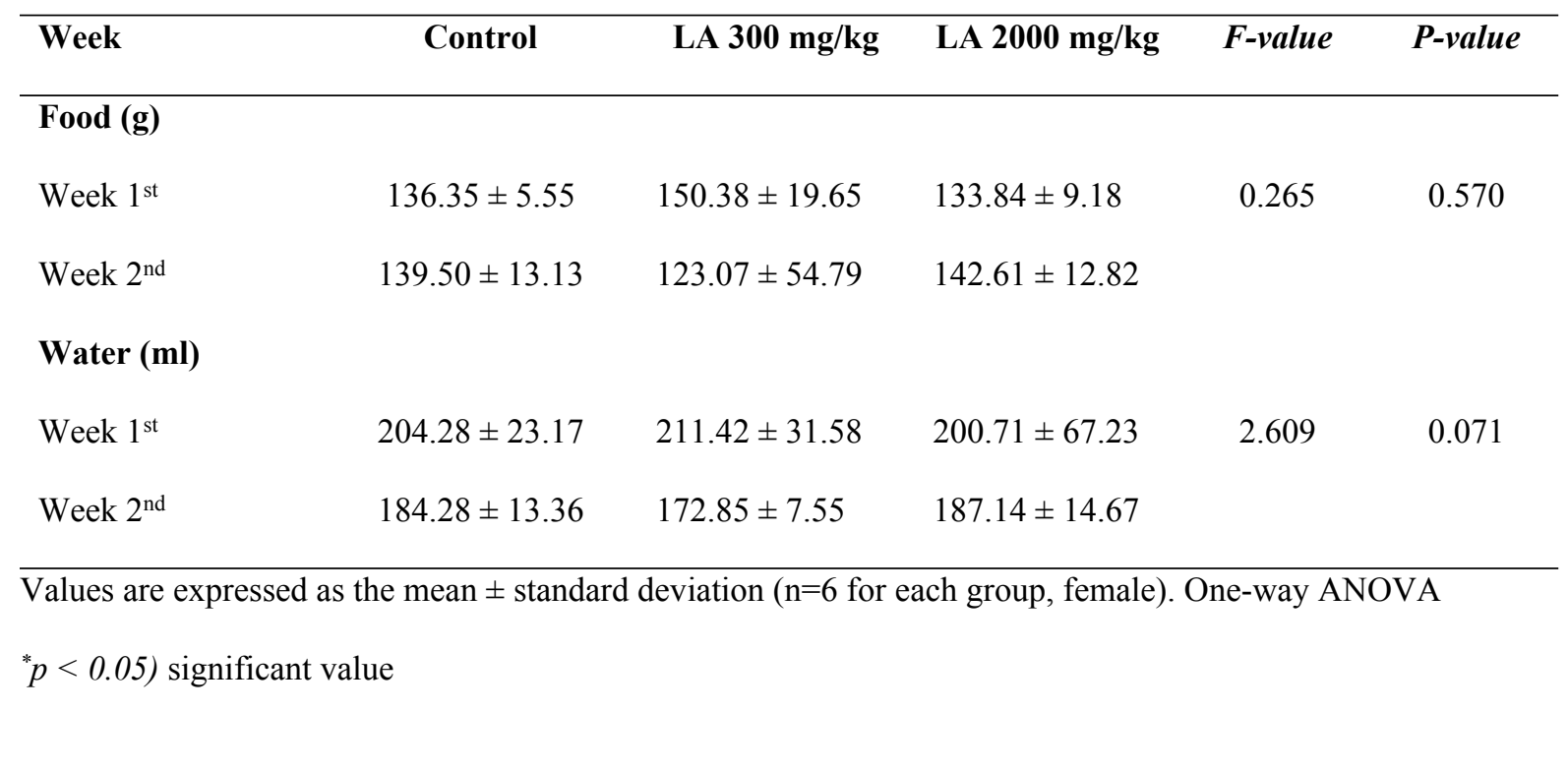




\section{Table 4 (on next page)}

Effect of LA on relative organ weight $(\mathrm{g})$

Values are expressed as the mean \pm standard deviation ( $n=6$ for each group, female). Oneway $\left.\operatorname{ANOVA}^{*} p<0.05\right)$ significant value 


\section{Table 4}

2 Effect of LA on relative organ weight (g).

\begin{tabular}{|c|c|c|c|c|c|}
\hline Organ & Control & LA 300 mg/kg & LA $2000 \mathrm{mg} / \mathrm{kg}$ & F-value & P-value \\
\hline Adrenal gland (left) & $0.018 \pm 0.001$ & $0.019 \pm 0.002$ & $0.019 \pm 0.002$ & 0.638 & 0.698 \\
\hline Adrenal gland (right) & $0.020 \pm 0.004$ & $0.018 \pm 0.003$ & $0.019 \pm 0.001$ & 0.537 & 0.595 \\
\hline Brain & $0.643 \pm 0.032$ & $0.626 \pm 0.069$ & $0.632 \pm 0.051$ & 0.162 & 0.852 \\
\hline Eye (left) & $0.041 \pm 0.002$ & $0.042 \pm 0.003$ & $0.044 \pm 0.003$ & 1.632 & 0.228 \\
\hline Eye (right) & $0.043 \pm 0.001$ & $0.043 \pm 0.002$ & $0.045 \pm 0.004$ & 1.218 & 0.323 \\
\hline Heart & $0.277 \pm 0.016$ & $0.290 \pm 0.019$ & $0.286 \pm 0.012$ & 0.960 & 0.405 \\
\hline Kidney (left) & $0.285 \pm 0.012$ & $0.300 \pm 0.024$ & $0.280 \pm 0.025$ & 1.480 & 0.259 \\
\hline Kidney(right) & $0.288 \pm 0.014$ & $0.297 \pm 0.020$ & $0.275 \pm 0.013$ & 2.640 & 0.104 \\
\hline Liver & $2.981 \pm 0.254$ & $2.918 \pm 0.367$ & $2.931 \pm 0.344$ & 0.062 & 0.940 \\
\hline Lungs & $0.476 \pm 0.038$ & $0.469 \pm 0.028$ & $0.502 \pm 0.029$ & 1.693 & 0.217 \\
\hline Ovary (left) & $0.032 \pm 0.008$ & $0.031 \pm 0.005$ & $0.033 \pm 0.010$ & 0.062 & 0.940 \\
\hline Ovary (right) & $0.033 \pm 0.005$ & $0.033 \pm 0.009$ & $0.033 \pm 0.006$ & 0.003 & 0.997 \\
\hline Pancreas & $0.292 \pm 0.043$ & $0.359 \pm 0.074$ & $0.306 \pm 0.056$ & 2.117 & 0.115 \\
\hline Spleen & $0.220 \pm 0.018$ & $0.209 \pm 0.027$ & $0.195 \pm 0.013$ & 2.284 & 0.136 \\
\hline Stomach & $0.754 \pm 0.111$ & $0.762 \pm 0.184$ & $0.939 \pm 0.238$ & 1.890 & 0.185 \\
\hline Urinary bladder & $0.037 \pm 0.003$ & $0.041 \pm 0.007$ & $0.037 \pm 0.004$ & 0.922 & 0.419 \\
\hline Uterus & $0.398 \pm 0.054$ & $0.445 \pm 0.211$ & $0.258 \pm 0.315$ & 2.579 & 0.109 \\
\hline Cervix/Vagina & $0.081 \pm 0.017$ & $0.075 \pm 0.011$ & $0.074 \pm 0.008$ & 0.445 & 0.445 \\
\hline
\end{tabular}

3 Values are expressed as the mean \pm standard deviation ( $\mathrm{n}=6$ for each group, female). One-way ANOVA $\left.4 \quad{ }^{*} p<0.05\right)$ significant value 


\section{Table 5 (on next page)}

Effect of LA on haematology

Values are expressed as the mean \pm standard deviation ( $n=6$ for each group, female). Oneway ANOVA $(*<0.05)$ significant value 


\section{Table 5}

2 Effect of LA on haematology

\begin{tabular}{llllll}
\hline Parameters & Control & LA 300 mg/kg & LA 2000 mg/kg & $\boldsymbol{F}$-value & $P$-value \\
\hline RBCs (10 $12 / \mathrm{L})$ & $7.350 \pm 0.187$ & $7.616 \pm 0.584$ & $7.666 \pm 0.216$ & 1.232 & 0.320 \\
WBCs $\left(10^{9} / \mathrm{L}\right)$ & $3.883 \pm 0.491$ & $3.866 \pm 1.237$ & $3.533 \pm 0.960$ & 0.163 & 0.851 \\
Platelets (109/L) & $953.333 \pm 68.677$ & $865.000 \pm 356.083$ & $846.666 \pm 154.749$ & 1.091 & 0.361 \\
Hb (g/dl) & $13.716 \pm 0.183$ & $13.783 \pm 0.523$ & $13.833 \pm 0.265$ & 0.553 & 0.587 \\
PCV (HCT\%) & $44.666 \pm 1.210$ & $36.833 \pm 18.082$ & $44.500 \pm 1.378$ & 0.393 & 0.682 \\
MCV fL & $52.333 \pm 16.366$ & $57.500 \pm 2.345$ & $57.333 \pm 2.732$ & 0.259 & 0.775 \\
MCH pg & $18.000 \pm 0.894$ & $17.666 \pm 1.211$ & $17.500 \pm 0.836$ & 0.377 & 0.692 \\
MCHC g/dL & $31.333 \pm 0.816$ & $31.500 \pm 0.836$ & $31.166 \pm 0.752$ & 0.260 & 0.775 \\
Neutrophil (\%) & $24.000 \pm 6.131$ & $25.500 \pm 7.582$ & $32.500 \pm 5.319$ & 3.002 & 0.080 \\
Lymphocyte (\%) & $64.000 \pm 5.966$ & $67.666 \pm 7.004$ & $61.833 \pm 4.215$ & 1.528 & 0.249 \\
Monocytes (\%) & $4.333 \pm 1.632$ & $3.500 \pm 1.760$ & $3.500 \pm 1.643$ & 0.492 & 0.621 \\
Eosinophils (\%) & $2.500 \pm 0.547$ & $2.333 \pm 0.516$ & $2.33 \pm 0.516$ & 0.200 & 0.821
\end{tabular}

3 Values are expressed as the mean \pm standard deviation ( $\mathrm{n}=6$ for each group, female). One-way ANOVA

$4 \quad\left({ }^{*} p<0.05\right)$ significant value

5

6 


\section{Table 6(on next page)}

Effect of LA on clinical biochemistry

Values are expressed as the mean \pm standard deviation ( $n=6$ for each group, female). Oneway $\left.\operatorname{ANOVA}^{*} p<0.05\right)$ significant value 


\section{Table 6}

2 Effect of LA on clinical biochemistry

\begin{tabular}{|c|c|c|c|c|c|}
\hline Clinical biochemistry & Control & $300 \mathrm{mg} / \mathrm{kg}$ & $2000 \mathrm{mg} / \mathrm{kg}$ & F-value & P-value \\
\hline Urea $(\mathrm{mmol} / \mathrm{L})$ & $6.633 \pm 1.040$ & $6.966 \pm 0.977$ & $8.200 \pm 1.240$ & 3.427 & 0.059 \\
\hline Creatinine (Umol/L) & $36.000 \pm 4.898$ & $28.833 \pm 13.044$ & $37.000 \pm 5.656$ & 1.579 & 0.239 \\
\hline Calcium $(\mathrm{mmol} / \mathrm{L}$ & $2.530 \pm 0.062$ & $2.500 \pm 0.109$ & $2.403 \pm 0.095$ & 3.126 & 0.073 \\
\hline Inorganic Phosphate $(\mathrm{mmol} / \mathrm{L})$ & $3.195 \pm 0.350$ & $3.401 \pm 0.642$ & $3.900 \pm 0.536$ & 2.871 & 0.088 \\
\hline Uric Acid (mmol/L) & $0.211 \pm 0.290$ & $0.106 \pm 0.048$ & $0.098 \pm 0.041$ & 0.813 & 0.462 \\
\hline Sodium $(\mathrm{mmol} / \mathrm{L})$ & $145.00 \pm 2.097$ & $145.833 \pm 1.471$ & $145.333 \pm 2.338$ & 0.263 & 0.772 \\
\hline Potassium (mmol/L) & $5.566 \pm 0.163$ & $5.900 \pm 0.433$ & $5.616 \pm 0.248$ & 2.105 & 0.156 \\
\hline Chloride $(\mathrm{mmol} / \mathrm{L})$ & $98.500 \pm 1.048$ & $99.000 \pm 2.449$ & $100.500 \pm 2.073$ & 1.711 & 0.214 \\
\hline $\mathrm{TC}(\mathrm{mmol} / \mathrm{L})$ & $2.033 \pm 0.436$ & $2.300 \pm 0.517$ & $1.966 \pm 0.307$ & 1.012 & 0.387 \\
\hline $\mathrm{HDL}(\mathrm{mmol} / \mathrm{L})$ & $0.623 \pm 0.082$ & $0.640 \pm 0.089$ & $0.590 \pm 0.098$ & 0.474 & 0.632 \\
\hline $\mathrm{LDL}(\mathrm{mmol} / \mathrm{L})$ & $0.868 \pm 0.198$ & $0.933 \pm 0.377$ & $0.733 \pm 0.398$ & 0.550 & 0.588 \\
\hline $\mathrm{TG}(\mathrm{Umol} / \mathrm{L})$ & $1.783 \pm 0.231$ & $1.483 \pm 0.487$ & $1.116 \pm 0.636$ & 2.879 & 0.087 \\
\hline Total HDL Ratio & $3.383 \pm 0.231$ & $3.516 \pm 0.444$ & $3.400 \pm 0.236$ & 0.309 & 0.739 \\
\hline Total protein $(\mathrm{g} / \mathrm{dL})$ & $70.833 \pm 2.926$ & $71.500 \pm 3.507$ & $66.833 \pm 3.816$ & 3.236 & 0.068 \\
\hline Albumin (g/dL) & $42.166 \pm 4.445$ & $44.500 \pm 4.888$ & $43.333 \pm 3.076$ & 0.461 & 0.639 \\
\hline Globulin(g/dL) & $24.333 \pm 1.211$ & $25.333 \pm 1.211$ & $23.666 \pm 0.816$ & 3.519 & 0.056 \\
\hline $\mathrm{A} / \mathrm{G}$ ratio & $1.800 \pm 0.894$ & $1.800 \pm 0.109$ & $1.833 \pm 0.121$ & 0.192 & 0.827 \\
\hline AP (IU/L) & $53.666 \pm 5.750$ & $57.166 \pm 11.669$ & $68.33 \pm 25.453$ & 1.293 & 0.303 \\
\hline SGOT /AST (IU/L) & $165.166 \pm 10.703$ & $200.166 \pm 35.204$ & $174.33 \pm 18.250$ & 3.315 & 0.056 \\
\hline SGPT /ALT(IU/L) & $36.666 \pm 1.966$ & $36.000 \pm 3.741$ & $40.500 \pm 19.065$ & 0.278 & 0.761 \\
\hline
\end{tabular}

3 Values are expressed as the mean \pm standard deviation ( $\mathrm{n}=6$ for each group, female). One-way ANOVA $\left.4 \quad{ }^{*} p<0.05\right)$ significant value

5 
Figure 1

Study design

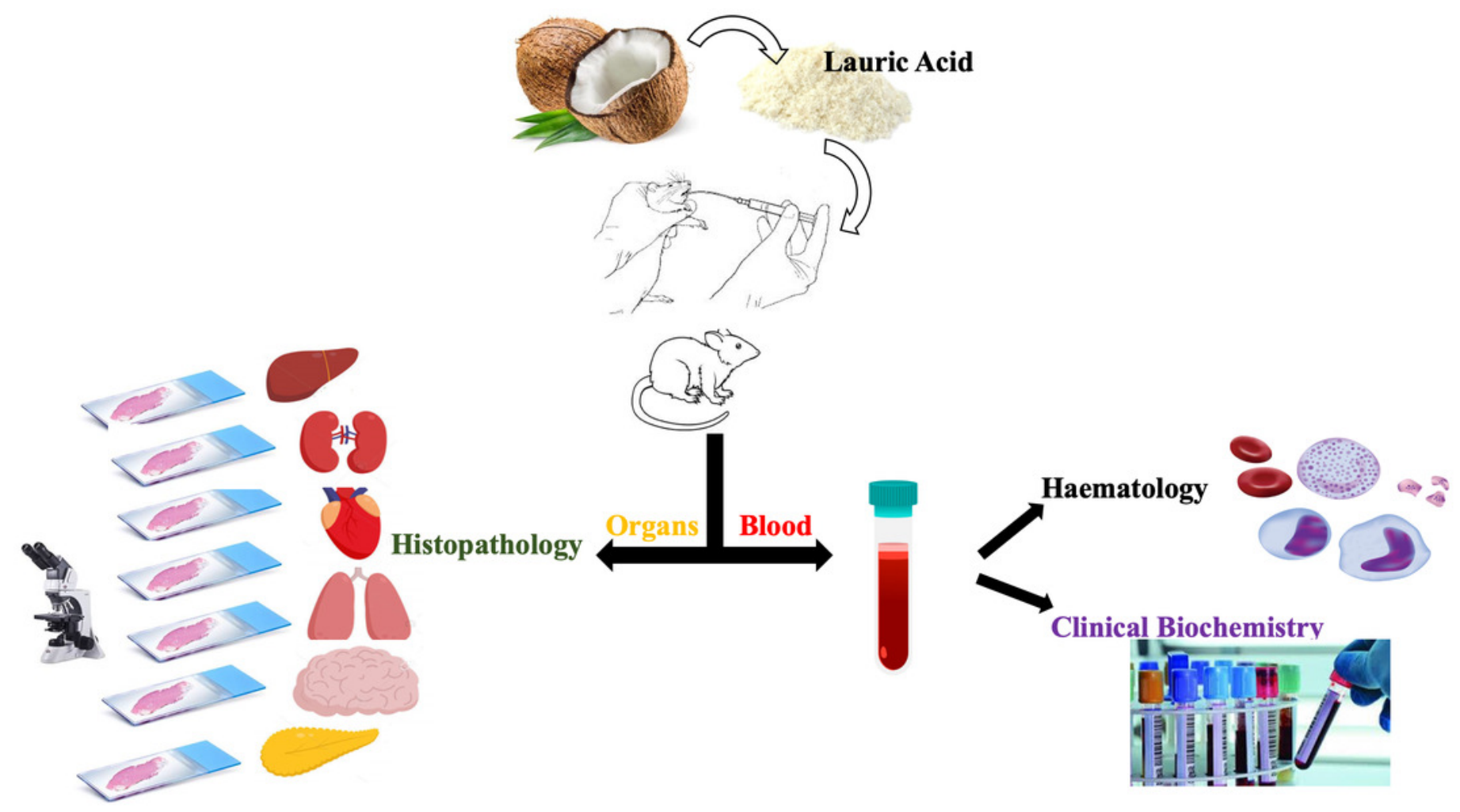




\section{Figure 2}

Macroscopic view of liver

Macroscopic view of liver tissues of female SD rats in acute oral toxicity study, LA treated animals presenting normal reddish colour closed to the normal control group, after a single oral doses of LA (300 mg/kg and $2000 \mathrm{mg} / \mathrm{kg}$ ).
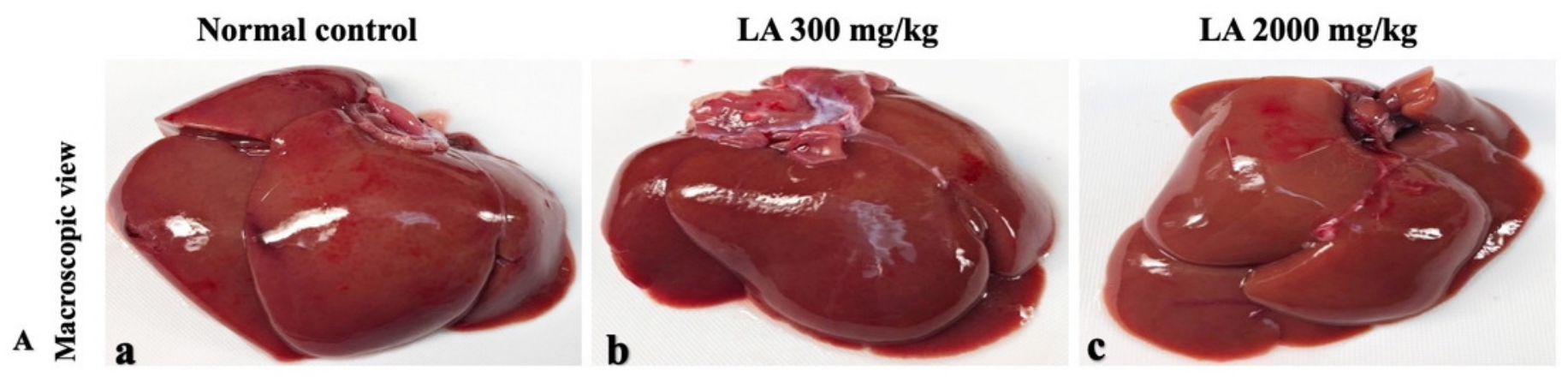


\section{Figure 3}

Microscopic analysis of liver

Microscopic analysis of liver tissues of female SD rats in acute oral toxicity study, presenting normal morphology after a single oral doses of LA (300 mg/kg and $2000 \mathrm{mg} / \mathrm{kg}$ ). $\mathrm{H} \& E(A)$, Masson trichrome (B), PAS (C), and Picro Sirius Red (D). 40x original magnification
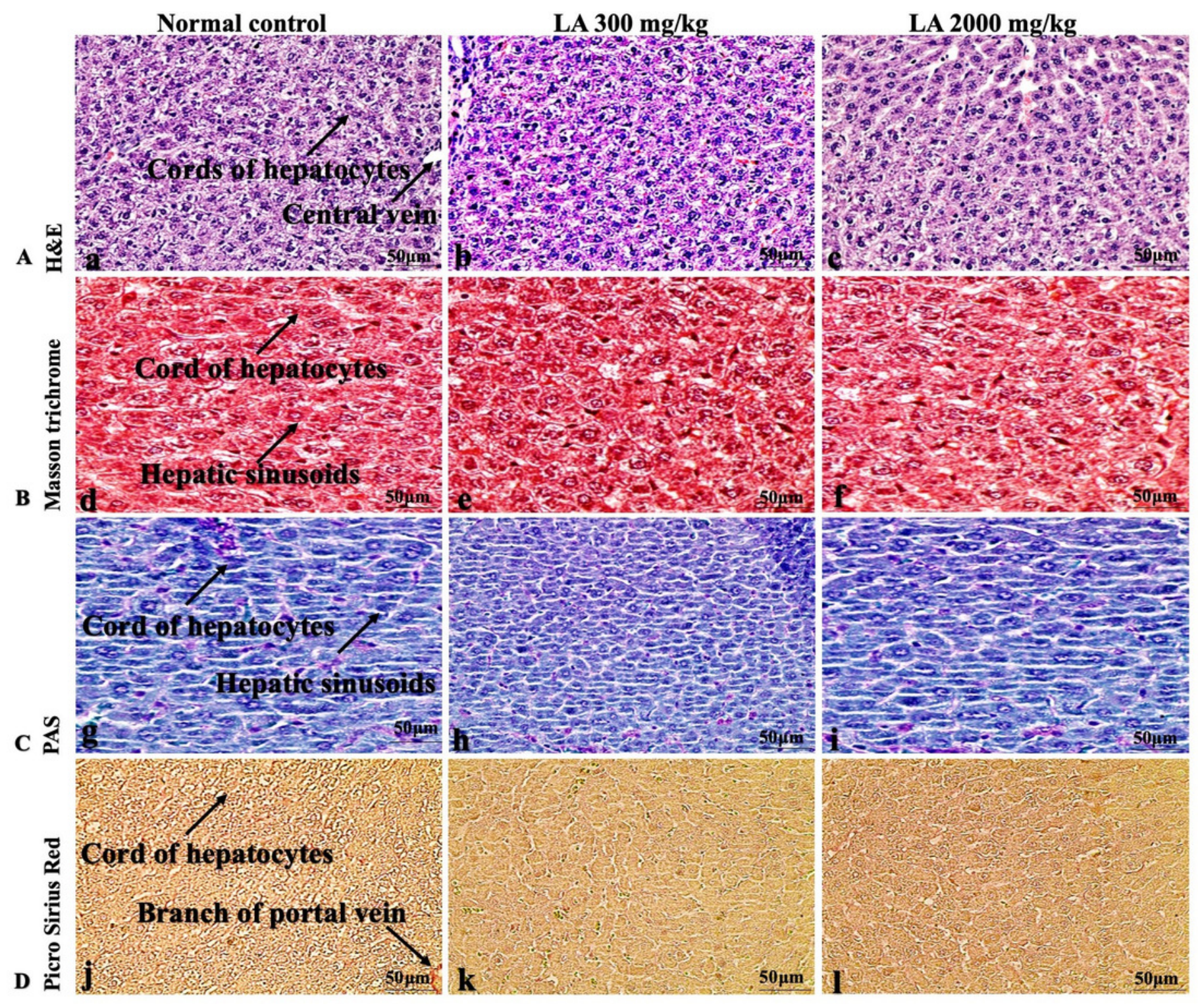


\section{Figure 4}

Macroscopic view of Kidney

Macroscopic view of kidneys of female SD rats in acute oral toxicity study, presenting normal shape and appearance after a single oral doses of LA (300 mg/kg and $2000 \mathrm{mg} / \mathrm{kg}$ ).
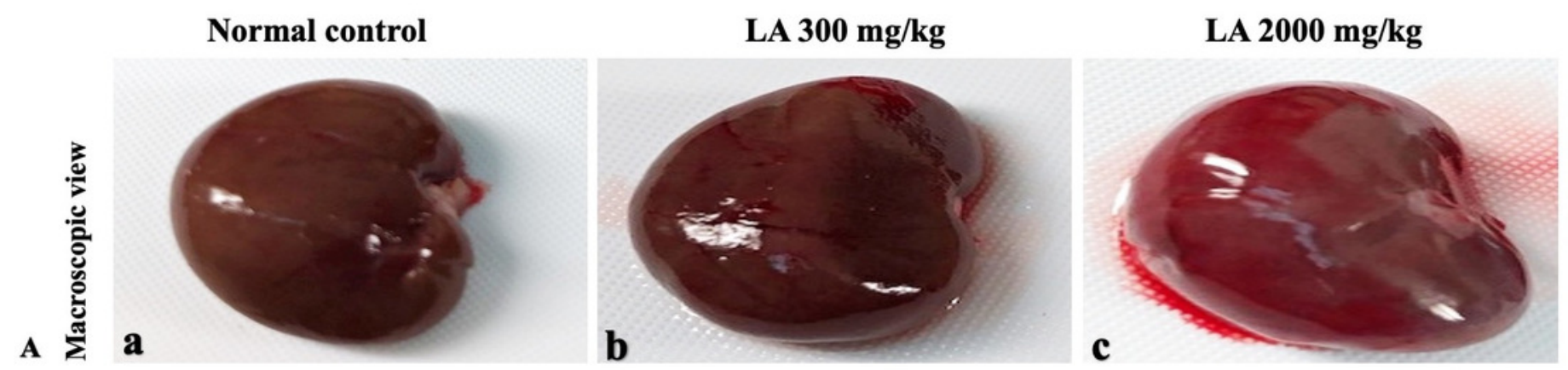


\section{Figure 5}

Microscopic analysis of kidney

Microscopic analysis of kidney tissues of female SD rats in acute oral toxicity study, presenting normal morphology after a single oral doses of LA (300 mg/kg and $2000 \mathrm{mg} / \mathrm{kg}$ ). $H \& E(A)$, Masson trichrome (B), PAS (C), and Picro Sirius Red (D). 40x original magnification.

A 蒌

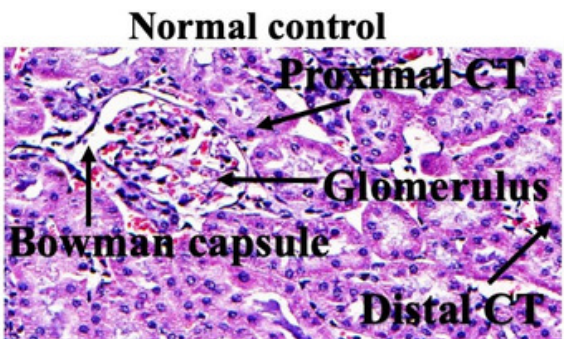

LA $300 \mathrm{mg} / \mathrm{kg}$
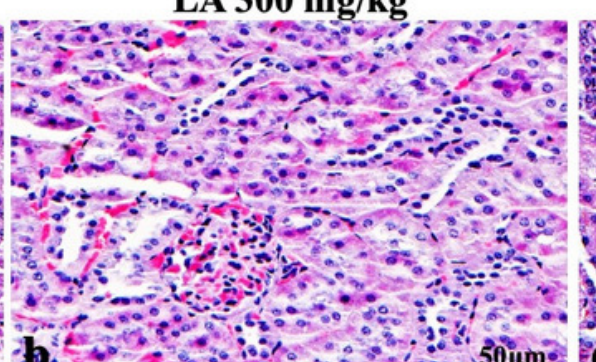

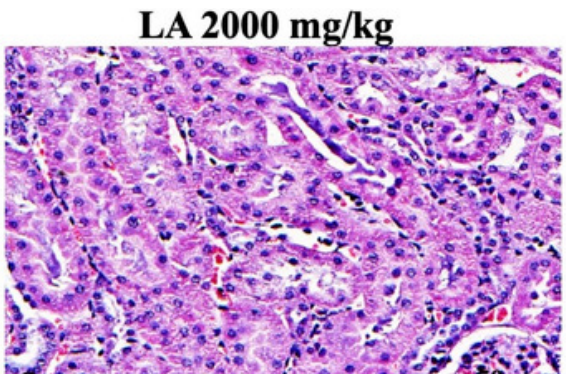

\section{LA $2000 \mathrm{mg} / \mathrm{kg}$}
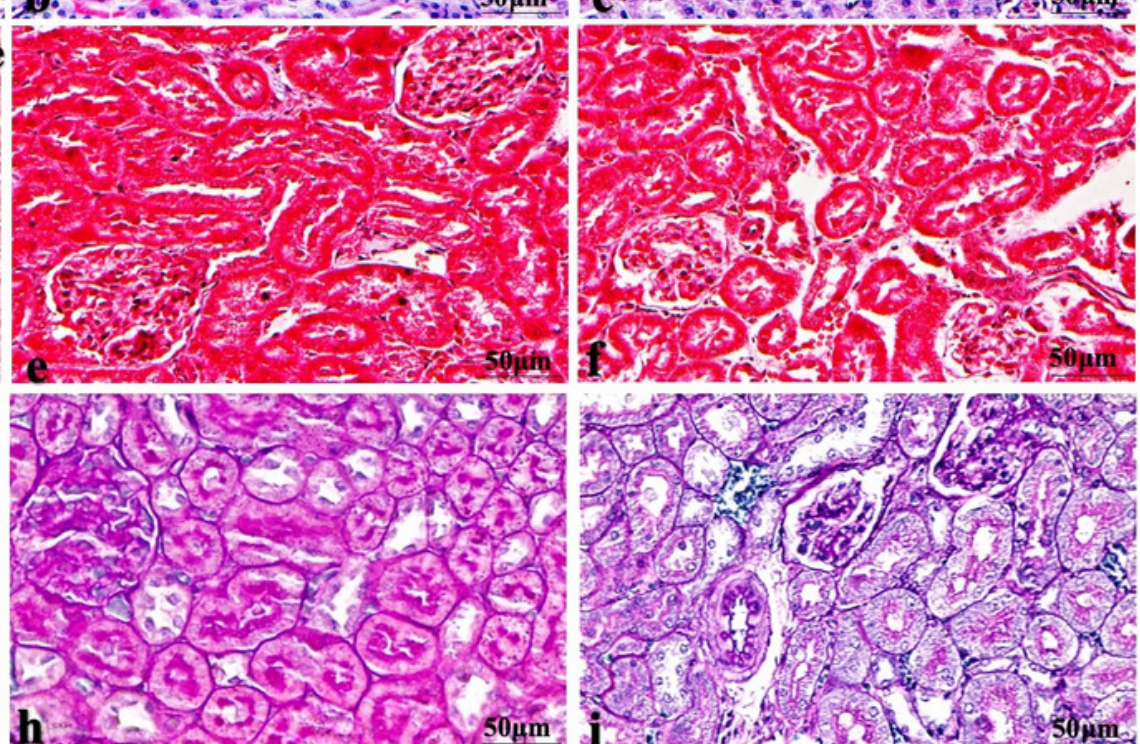

$c \stackrel{g}{a}$

\section{Bovina capsite}
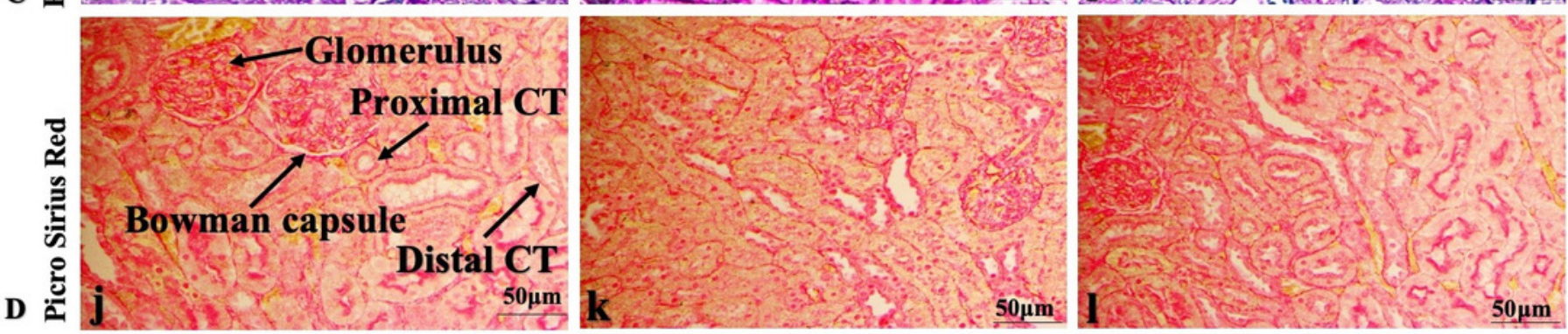


\section{Figure 6}

Macroscopic view of heart

Macroscopic view of heart of female SD rats in acute oral toxicity study, presenting normal shape and appearance after a single oral doses of LA (300 mg/kg and $2000 \mathrm{mg} / \mathrm{kg}$ ).
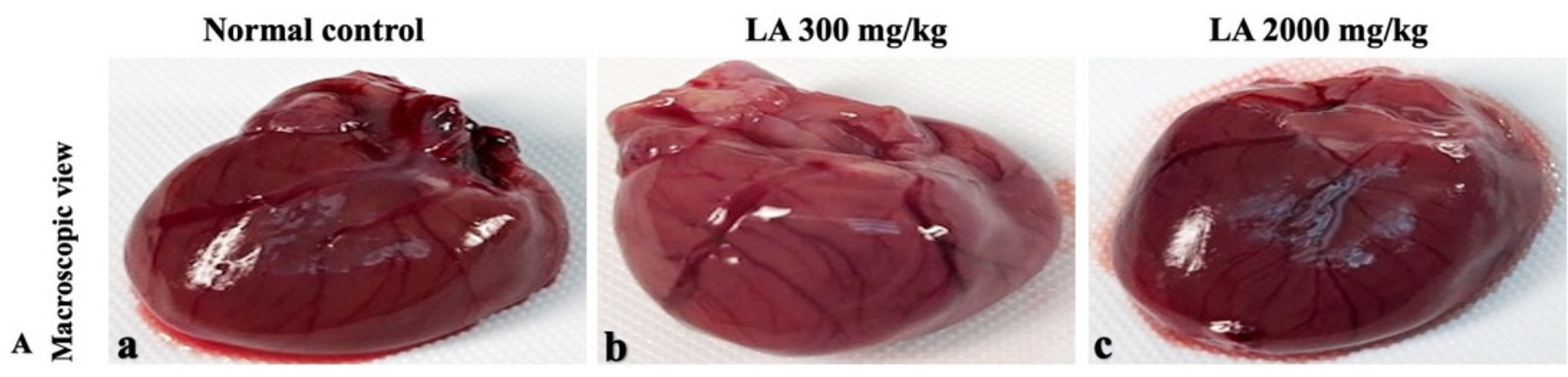


\section{Figure 7}

Microscopic analysis of heart

Microscopic analysis of heart tissues of female SD rats in acute oral toxicity study, presenting normal morphology after a single oral doses of LA (300 mg/kg and $2000 \mathrm{mg} / \mathrm{kg}$ ). H\&E (A), Masson trichrome (B), PAS (C), and Picro Sirius Red (D). 40x original magnification.

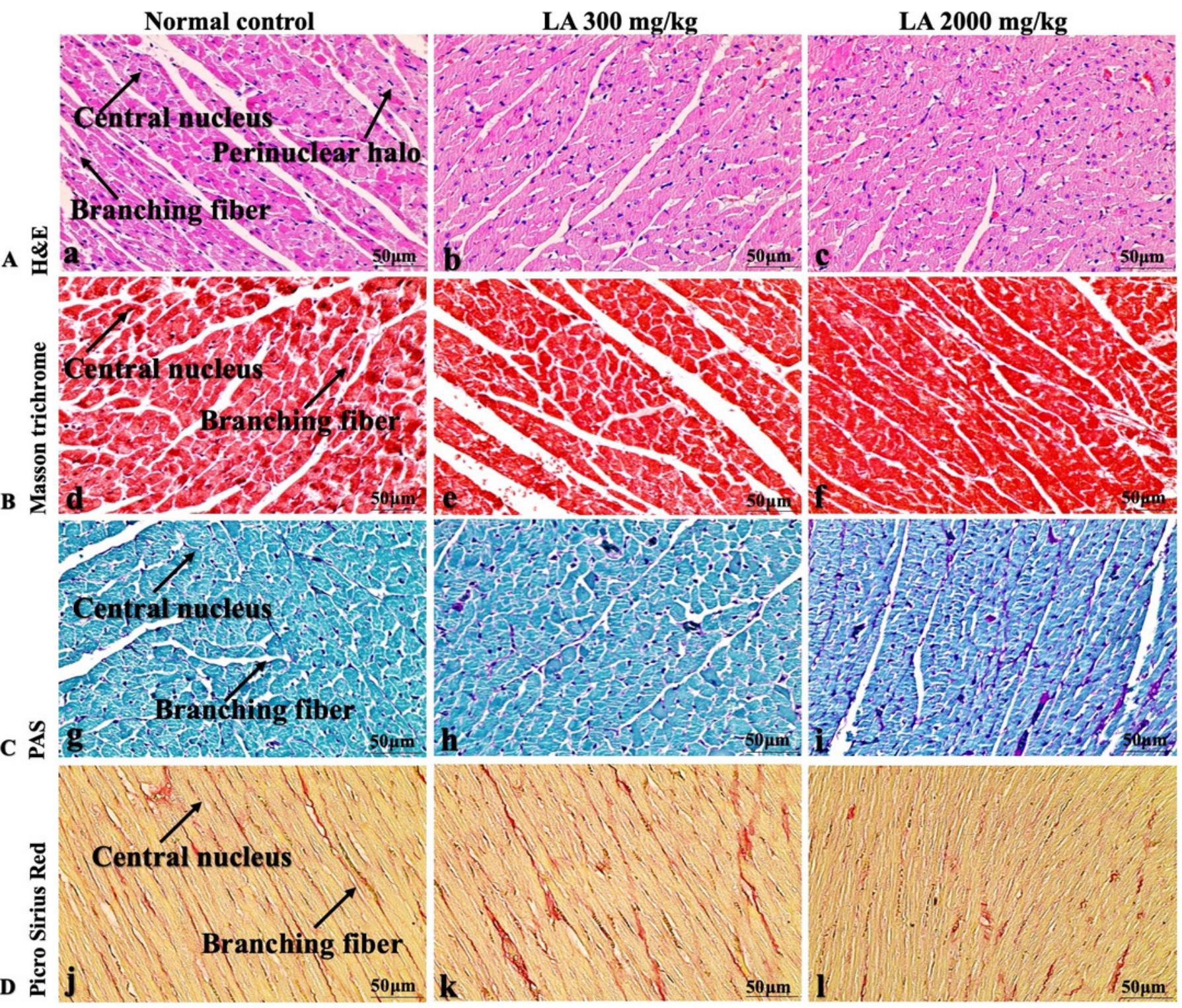


Figure 8

Macroscopic view of lungs

Macroscopic view of lungs of female SD rats in acute oral toxicity study, presenting normal shape and appearance after a single oral doses of LA (300 mg/kg and $2000 \mathrm{mg} / \mathrm{kg}$ ).
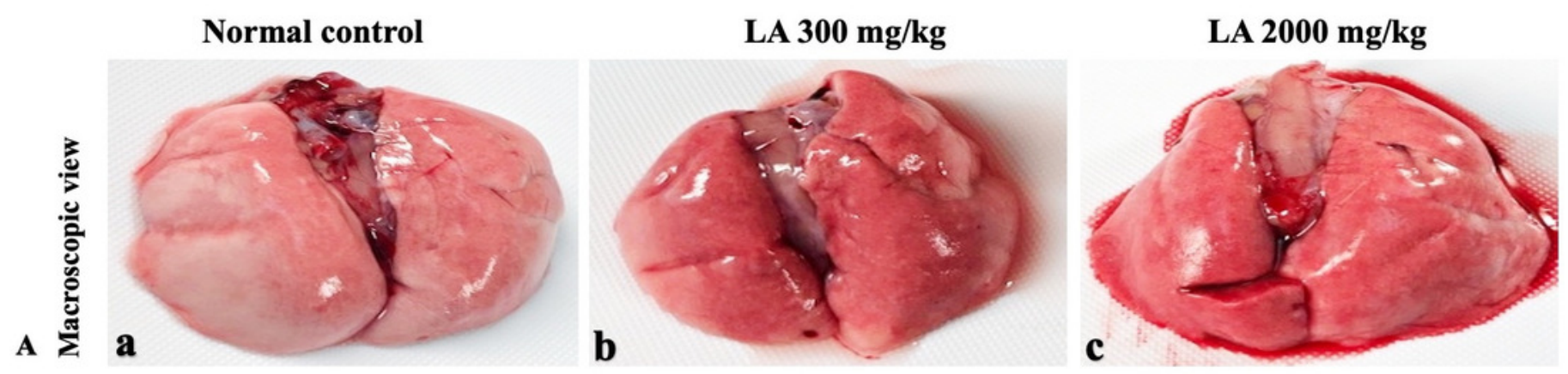


\section{Figure 9}

Microscopic analysis of lungs

Microscopic analysis of lungs tissues of female SD rats in acute oral toxicity study, presenting normal morphology after a single oral doses of LA (300 mg/kg and $2000 \mathrm{mg} / \mathrm{kg}$ ). $H \& E$ A), Masson trichrome (B), PAS (C), and Picro Sirius Red (D). 40x original magnification.

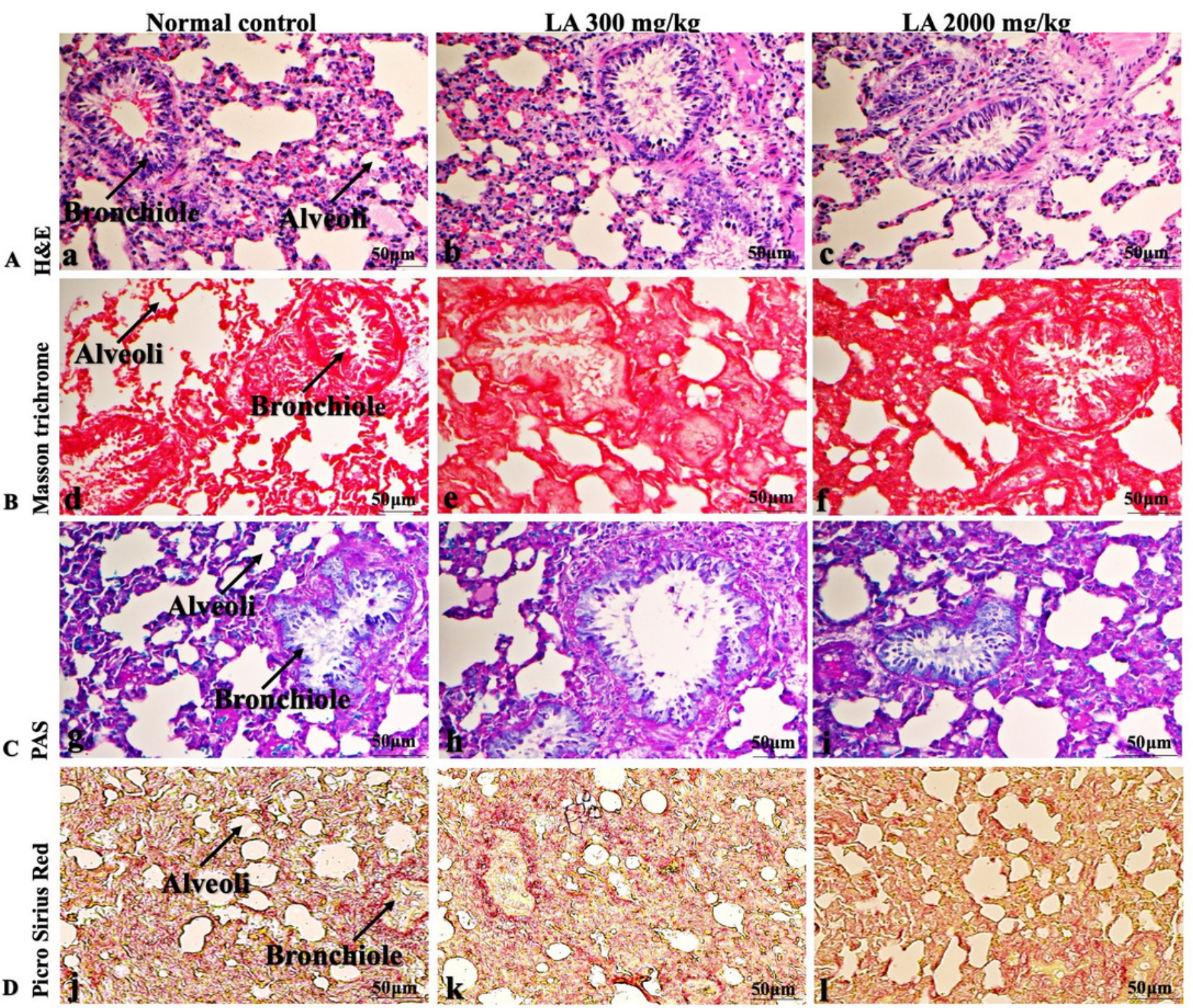




\section{Figure 10}

Macroscopic view of brain

Macroscopic view of brain of female SD rats in acute oral toxicity study, presenting normal shape and appearance after a single oral doses of LA (300 mg/kg and $2000 \mathrm{mg} / \mathrm{kg}$ ).
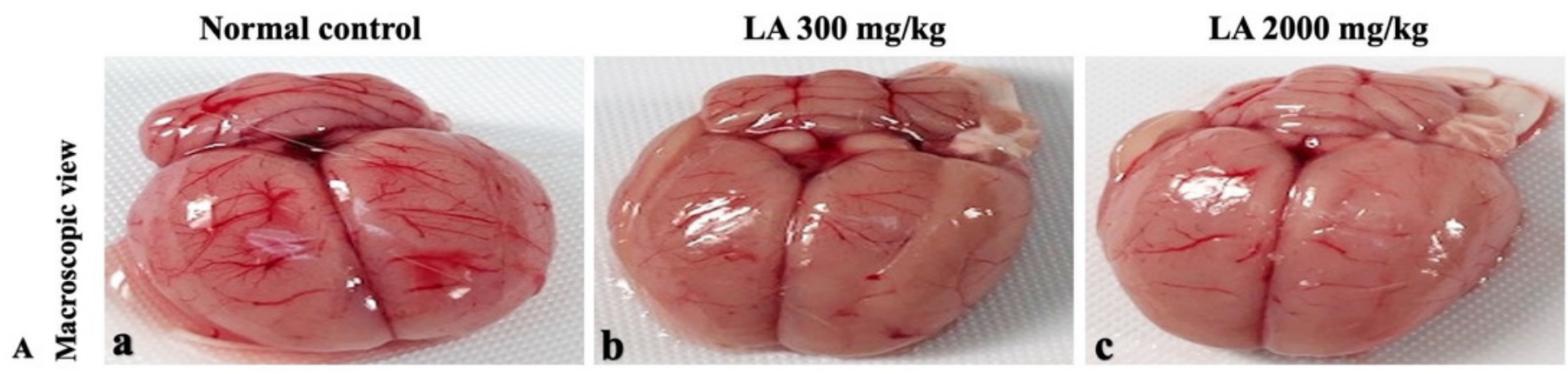


\section{Figure 11}

Microscopic analysis of brain

Microscopic analysis of brain tissues of female SD rats in acute oral toxicity study, presenting normal morphology after a single oral doses of LA (300 mg/kg and $2000 \mathrm{mg} / \mathrm{kg}$ ). H\&E A), Masson trichrome (B), PAS (C), and Picro Sirius Red (D). 40x original magnification.

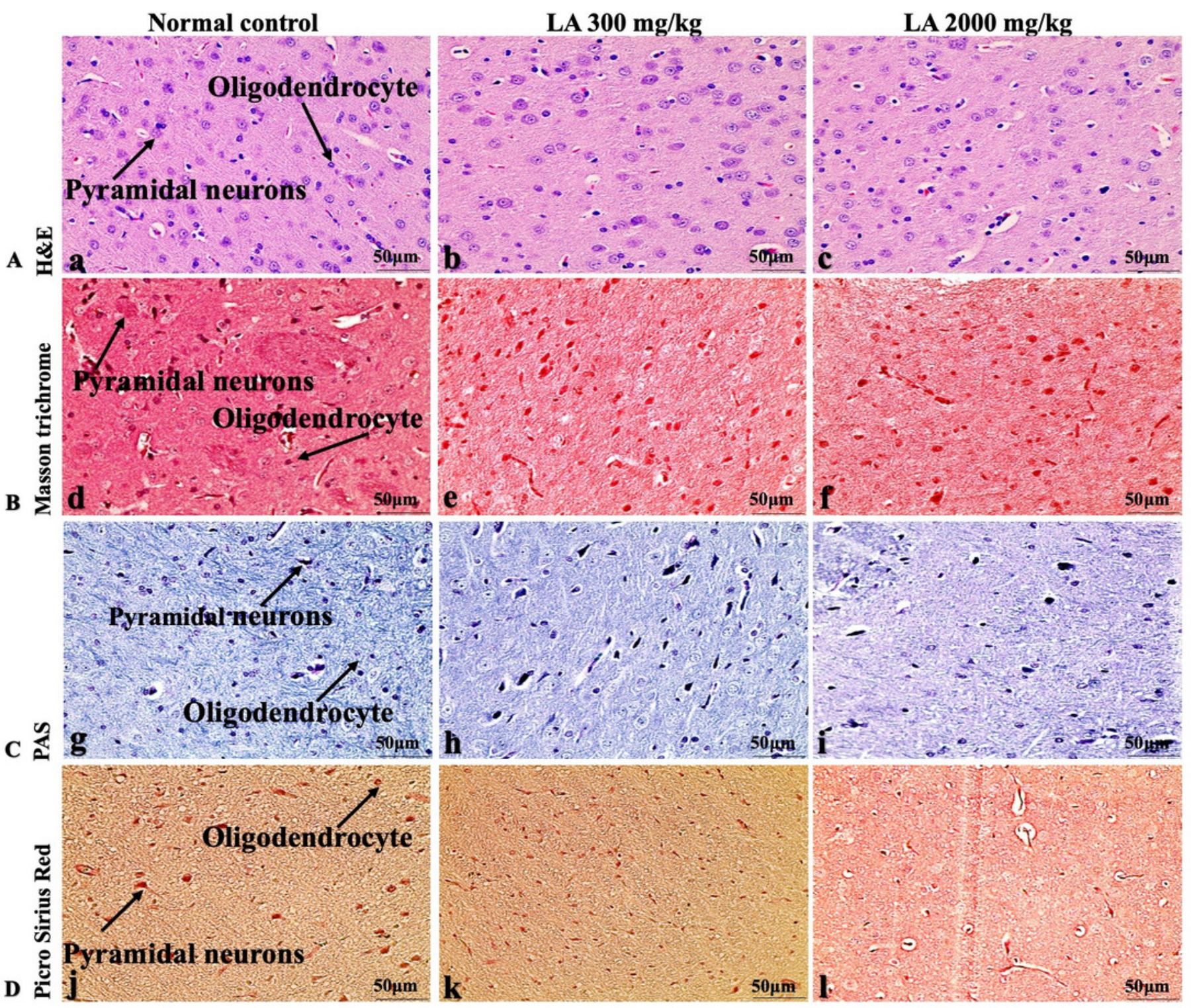




\section{Figure 12}

Macroscopic view of spleen

Macroscopic view of spleen of female SD rats in acute oral toxicity study, presenting normal shape and appearance after a single oral doses of LA (300 mg/kg and $2000 \mathrm{mg} / \mathrm{kg}$ ).
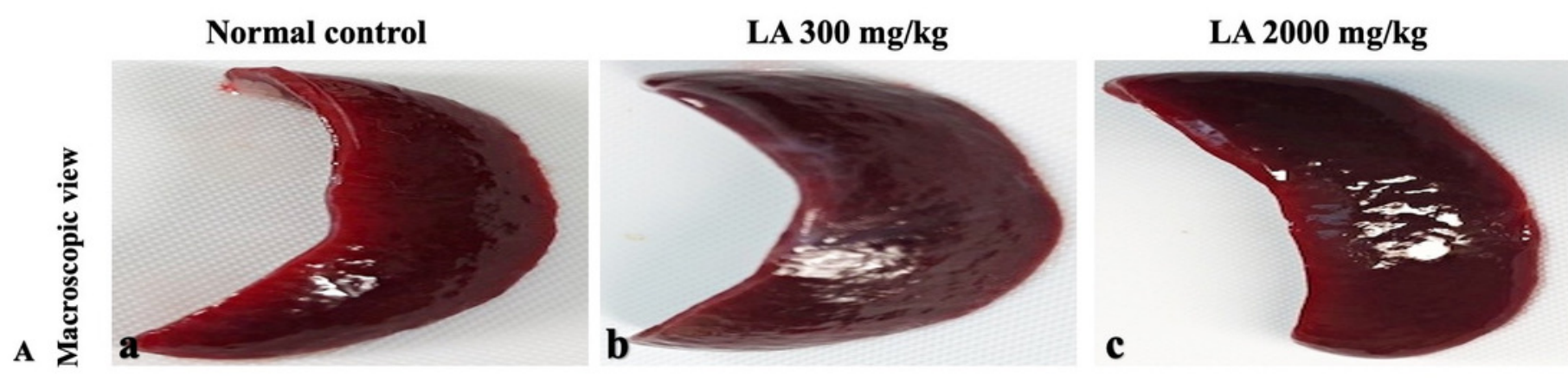


\section{Figure 13}

Microscopic analysis of spleen

Microscopic analysis of spleen tissues of female SD rats in acute oral toxicity study, presenting normal morphology after a single oral doses of LA (300 mg/kg and $2000 \mathrm{mg} / \mathrm{kg}$ ). $H \& E$ A), Masson trichrome (B), PAS (C), and Picro Sirius Red (D). 40' original magnification.
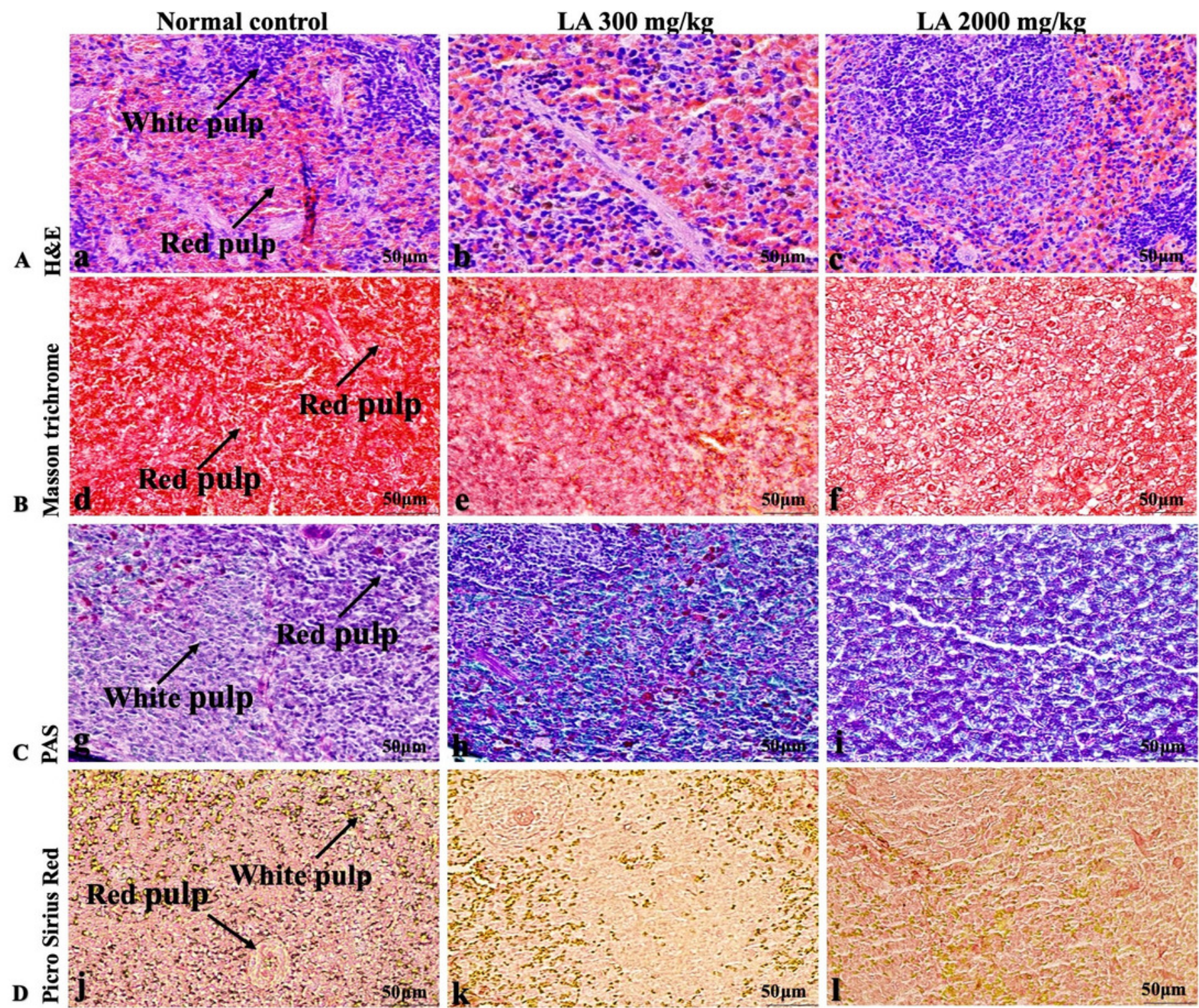

C 2

$\mathrm{D}$ 


\section{Figure 14}

Macroscopic view of pancreas

Macroscopic view of pancreas of female SD rats in acute oral toxicity study, presenting normal shape and appearance after a single oral doses of LA (300 mg/kg and $2000 \mathrm{mg} / \mathrm{kg}$ ).
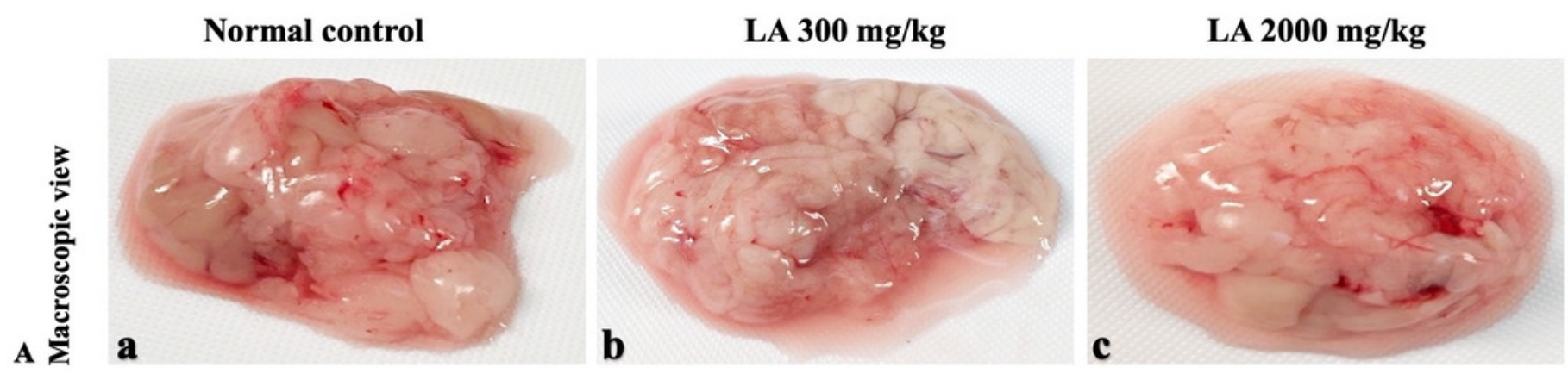


\section{Figure 15}

Microscopic analysis of pancreas

Microscopic analysis of pancreas tissues of female SD rats in acute oral toxicity study, presenting normal morphology after a single oral doses of LA (300 mg/kg and $2000 \mathrm{mg} / \mathrm{kg}$ ). H\&E A), Masson trichrome (B), PAS (C), and Picro Sirius Red (D). 40x original magnification.

A
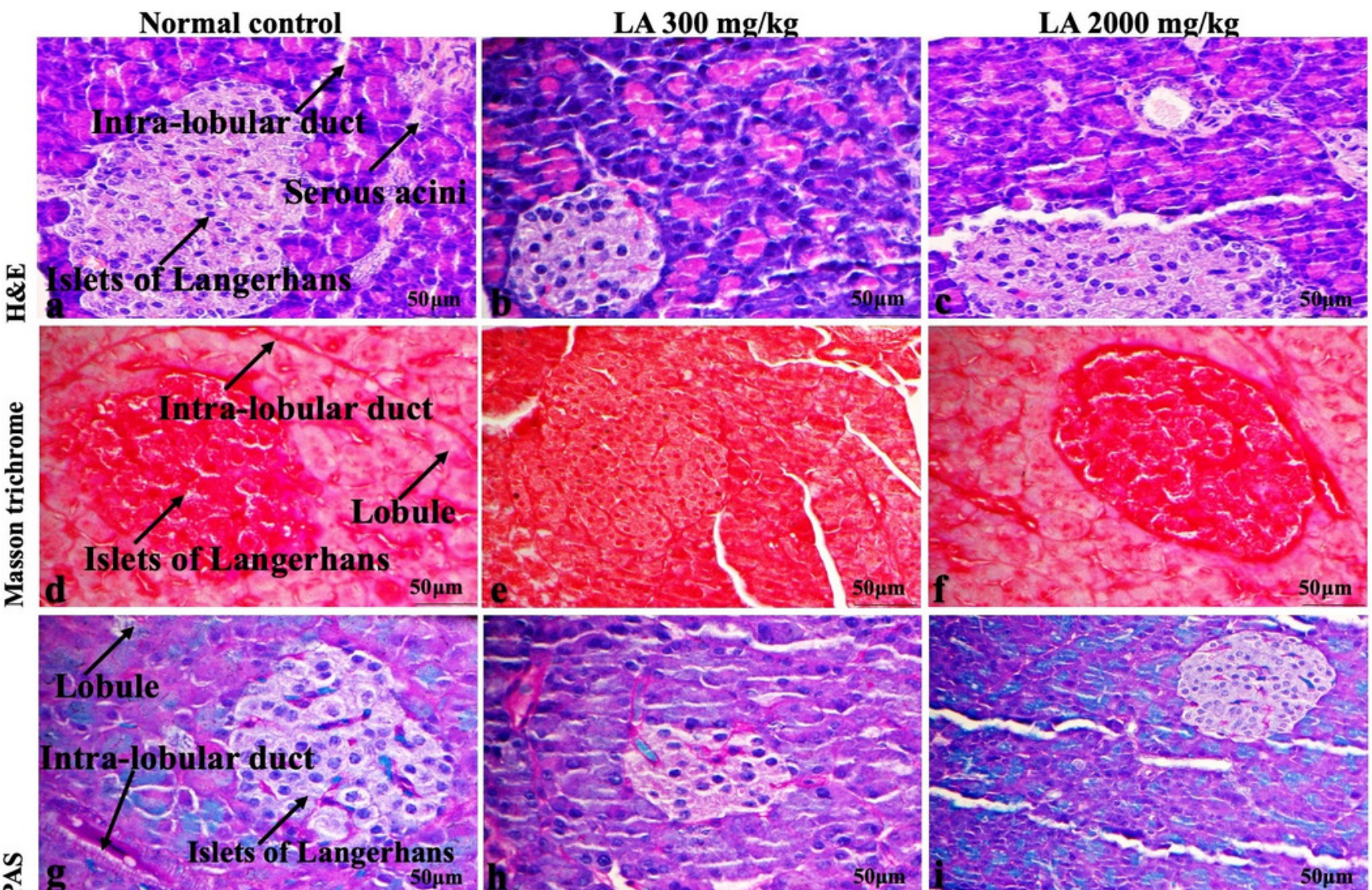

c
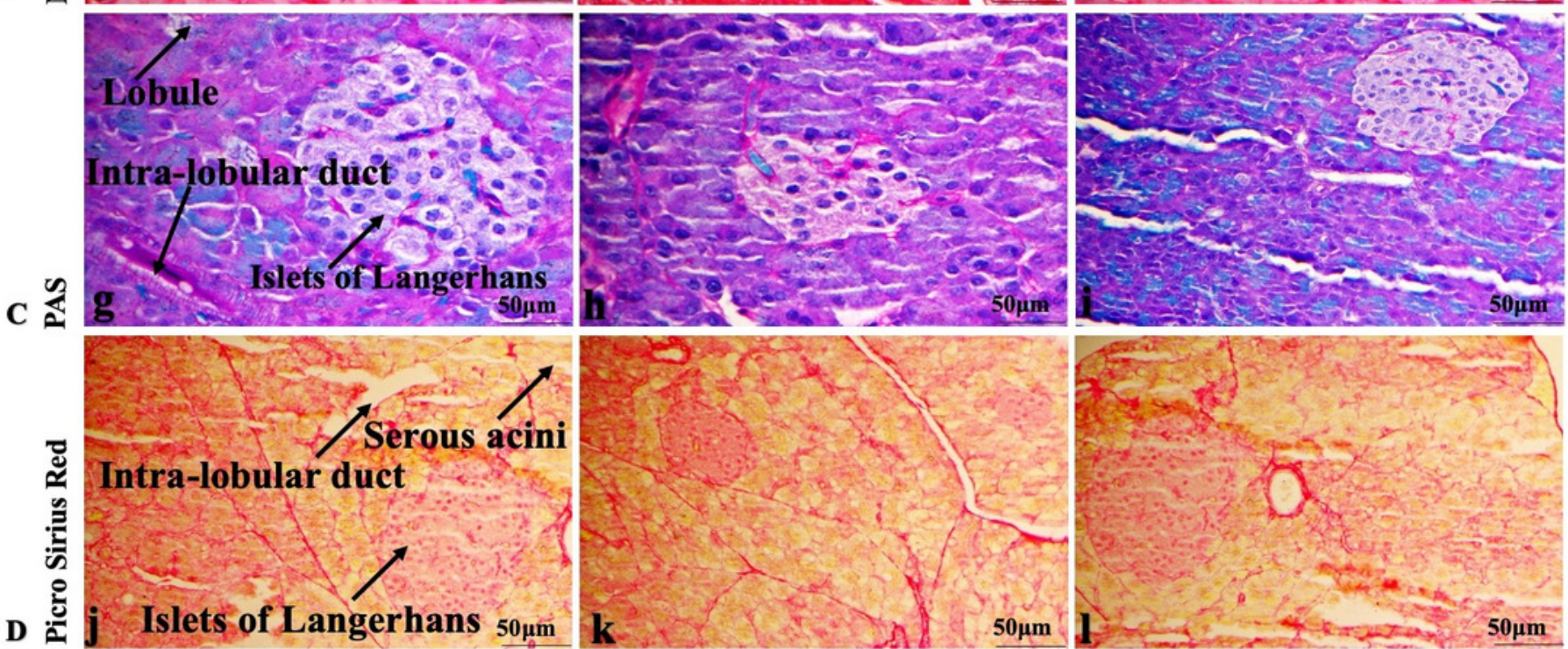